\title{
READING A LANDSCAPE
}

\author{
Raffaele Gambassi
}

Via Salceto 87, Poggibonsi, Siena, Italy

raffaele@architettogambassi.it

\begin{abstract}
I have traveled often through the streets of my country by car, motorcycle, bicycle and on foot, and each time the landscape has always accompanied me like a faithful companion. Whenever I stopped to look at this land, whether up close or from afar, I continually see with eyes scrutinizing every detail of every corner. There is an irresistible attraction that has always pushed me to immerse myself in that view, as if it was a gentle reminder to enjoy that beauty.

The landscape does not exist by itself: the landscape exists when people observe the terrain and the landscape becomes subjective based on their personal experience of that view. But the landscape is also objective when it becomes the bearer of the cultural identity of a land and of its people.

The landscape may seem eternal and unchanging in its vastness and its characteristics, but in reality landscapes do change like a living being, giving us the feeling of a "permanent transformation" that is the great charm of the landscape.

The landscape is like a book that we can read, with its own grammar, signs and meanings, or it is like a musical score with its own notes, rhythms and pitches. Each element that makes up the landscape can contribute to the concept of beauty if it is harmoniously linked with the others. Unfortunately there are too many cases in which human intervention creates grammatical errors in the text or false notes in the music. As a whole, the landscape is a significant indicator of social transformation and the level of quality of life of a community.
\end{abstract}

\section{Keywords}

Landscape, terrain, painting, natural scenery, view, perception.

\section{Definition of Landscape}

"Landscape is a certain part of the terrain, as it is conceived by people, whose character derives from the natural and / or human factors and their interrelations."

(European Landscape Convention - Florence - 2000)
"View: a panoramic scene of a given point of a terrain, with reference to its characteristic natural beauty or of places of historical and artistic interest; all the complexities of the natural assets that are a fundamental part of the ecological environment to defend and preserve."

(Encyclopedic Italian Dictionary Treccani)

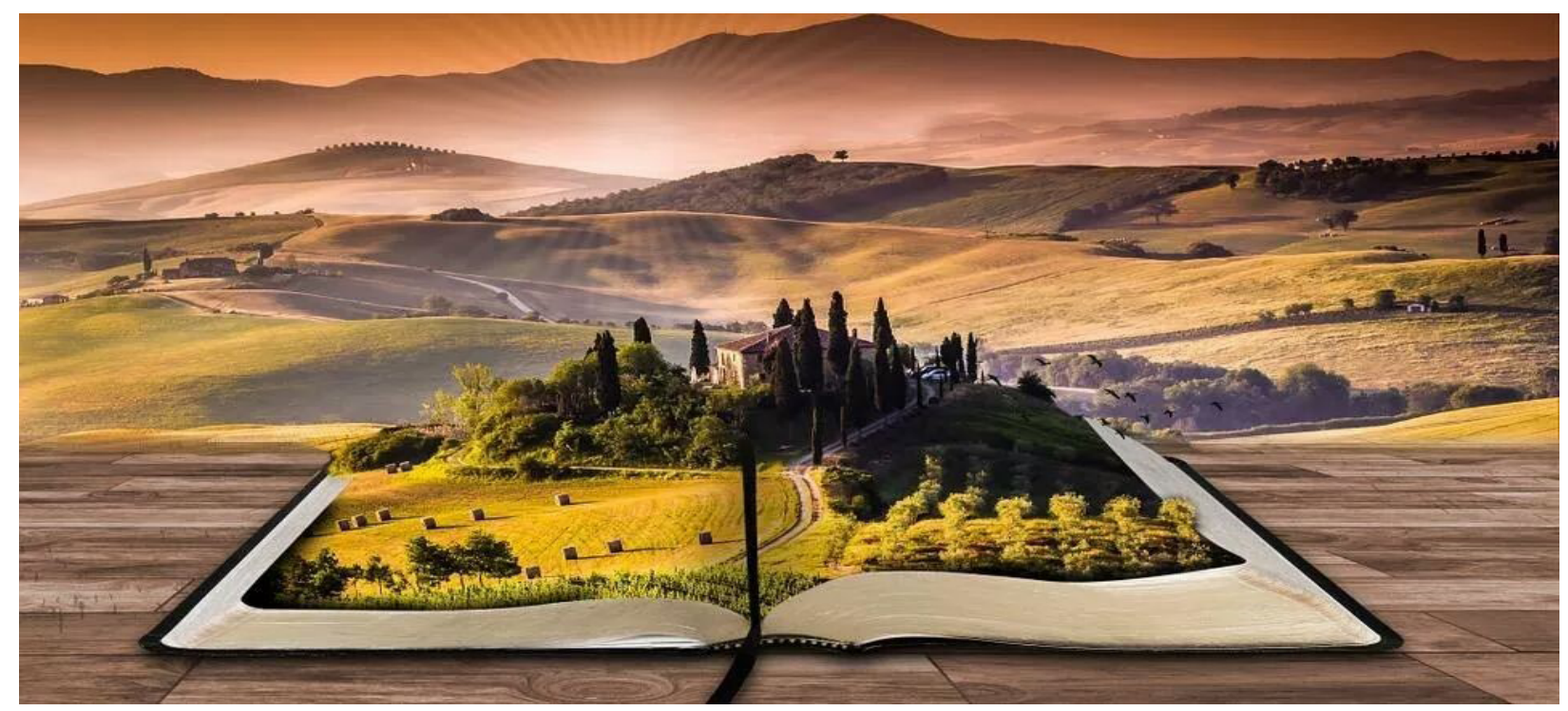

Figure 1. The landscape is like a book to read 


\section{Architecture and Engineering Volume 2 Issue 1}

\section{Landscape $=$ Subject + Nature}

(Michael Jacob)

"A view is not a landscape when nature is randomly scattered upon a piece of land; a view is transformed to a landscape by nature in its individuality and by the human eye."

(Georg Simmel, Philosophy of the landscape).

"A section or expanse of rural scenery, usually extensive, that can be seen from a single viewpoint."

(Thesaurus.com)

"A large area of countryside, especially in relation to its appearance."

(Cambridge Dictionary)

"All the visible features of an area of land, often considered in terms of their aesthetic appeal."

(Oxford Dictionary)

"A painting, drawing, photograph, depicting natural scenery."

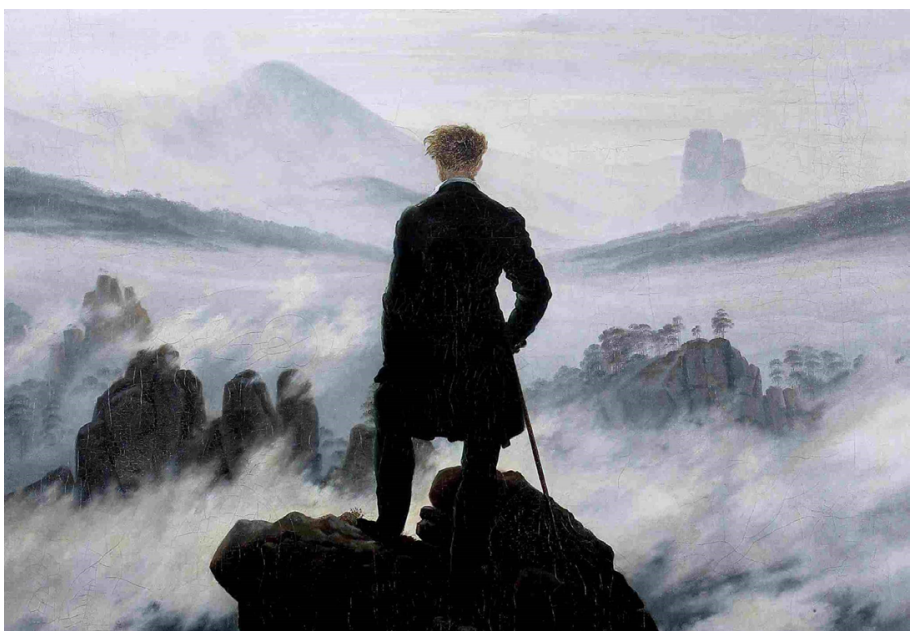

\section{(British Dictionary)}

"The landscape is the shape of the environment." (Barocchi R., Italian Urban Dictionary)

\section{Components of the landscape}

Environment: everything (that part of the Universe) in the surroundings or conditions in which a person, animal, or plant lives or operates.

Landscape: a section or expanse of rural scenery, usually extensive, that can be seen from a single viewpoint.;

View: the landscape as you see it from a certain place looking in a certain direction;

Picture: how each of us perceives a certain view; a design or representation made by various means (as painting, drawing, or photography) that is so vivid or graphic as to suggest a mental image or give an accurate idea of something.

Perceiver: a person who becomes aware of, knows or understands a certain landscape at a certain time, from a certain point, looking in a certain direction.

Figure 2, 3. Romantic paintings with people seeing landscapes

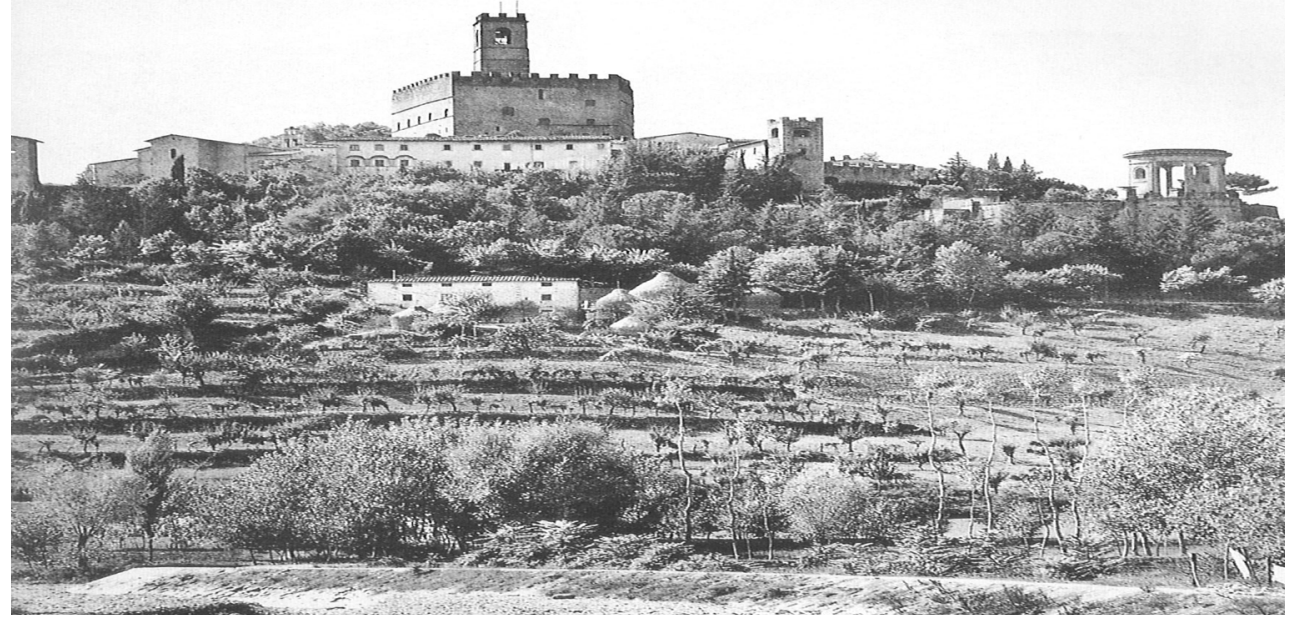

Figure 4. Guidi Palace - Poppi - Italy - 1930 


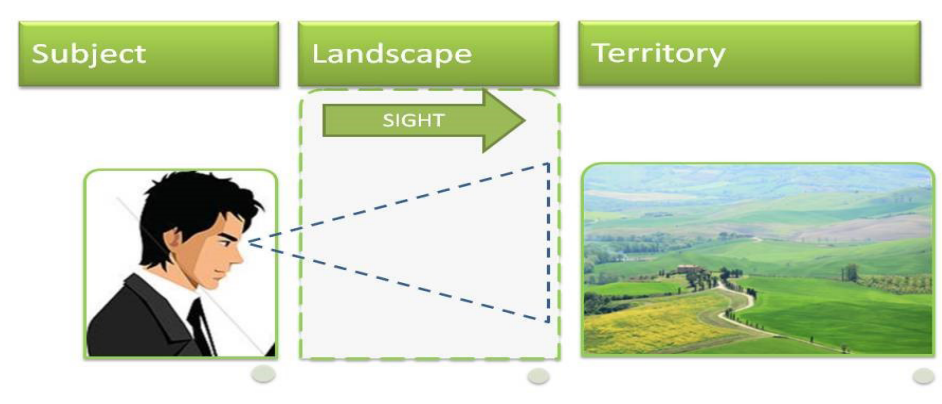

FIELD OF VIEW IN THE VERTICAL PLANE

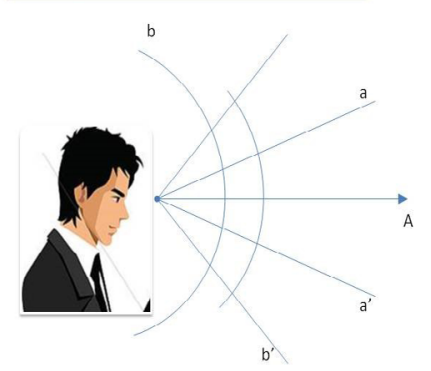

$A=$ optical axis

$a-a^{\prime}=$ viewing cone $\left(60^{\circ}\right)$

$b-b^{\prime}=$ viewing cone of perceiving motion $\left(120^{\circ}\right)$
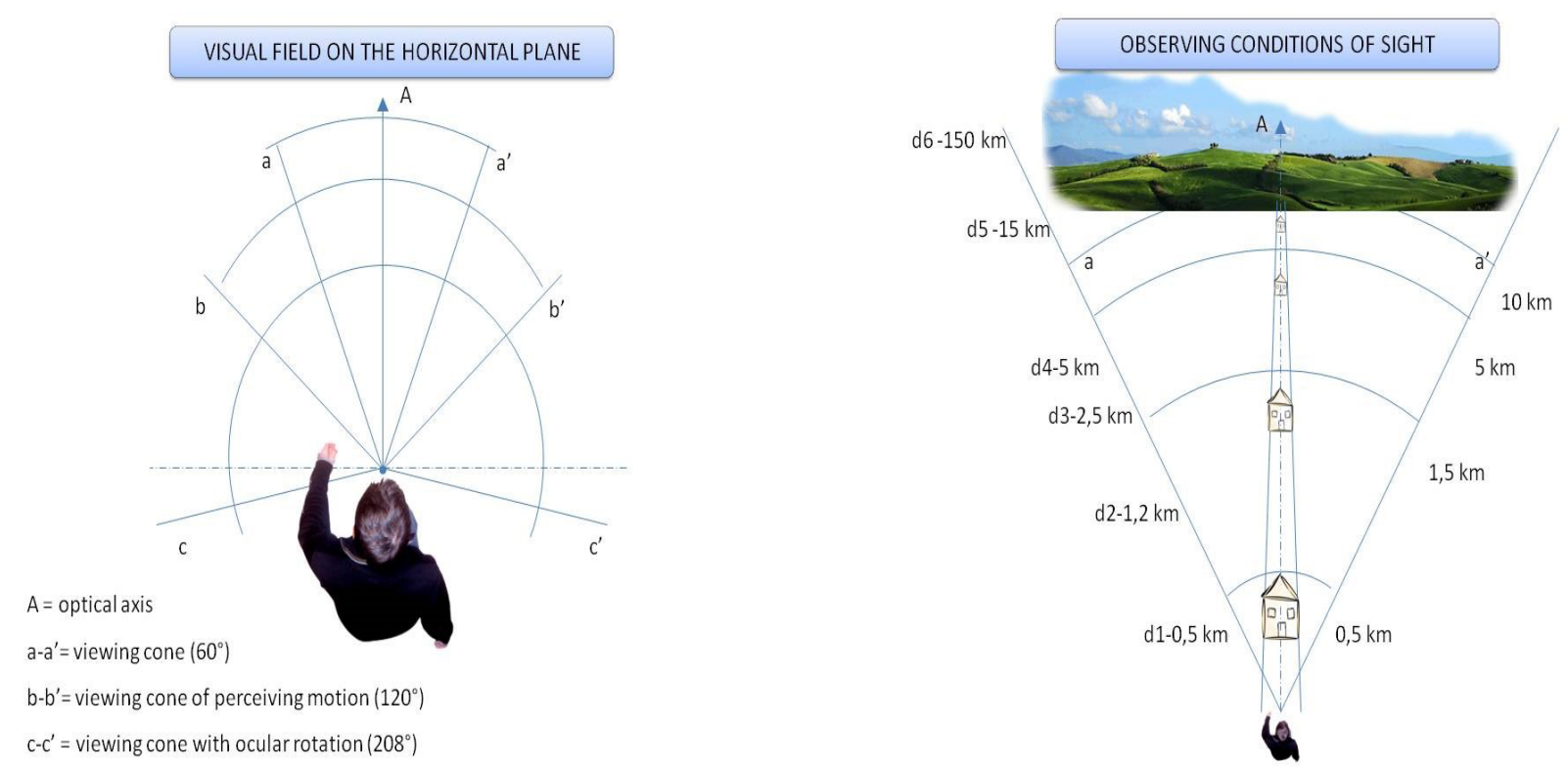

$A=$ optical axis

$\mathrm{a}-\mathrm{a}^{\prime}=$ viewing cone $\left(60^{\circ}\right)$

$\mathrm{d} 1=$ Proximity area (recognition of small details)

$\mathrm{d} 2=$ Near contest area distance between 0,5 and 1,2 km (good recognition of the scene's elements)

$\mathrm{d} 3=$ Intermediate context area distance between 1,2 and 2,5 km

$\mathrm{d} 4=$ Away context area distance between 2,5 and $5 \mathrm{~km}$

$\mathrm{d} 5=$ Wide area (descending recognition of large elements) distance between 5 and $15 \mathrm{~km}$ $\mathrm{d} 6=$ Backdrops also up to $150 \mathrm{~km}$ with high profiles and clear sky

Figure 5. A landscape exists when people look at it: note the optical axis and visual fields above 


\section{Looking at a landscape}

The landscape is what we see: this is how our sight attaches to a point; it is an impression of the senses. The perception of a landscape is therefore a sentimental impression. Look far and near: depending on where you live, landscapes train the eye to a different visual depth. The great plains of the great nations (USA, Russia) train the eye for long, faraway gazes at the breadth and depth of a terrain, while the hilly and constructed nations (Italy) train the eye for shorter views because the landscape is restricted in size and is developed in small plots (patchwork landscape.)

\section{Significance of the landscape}

What does "landscape" means? The answers are varied, depending on the perceiver, such as: the urban planner, the architect, the farmer, the geographer, the philosopher, the psychologist, the optometrist, the anthropologist, the painter, the musician, the tourist.

The image that each of us has of a place so dependent on local forms, which are the same for everyone. However, the perceiver's point of view, the direction in which the perceiver looks and the perceiver's personality contribute to how the image of those forms, such as a forest is perceived.

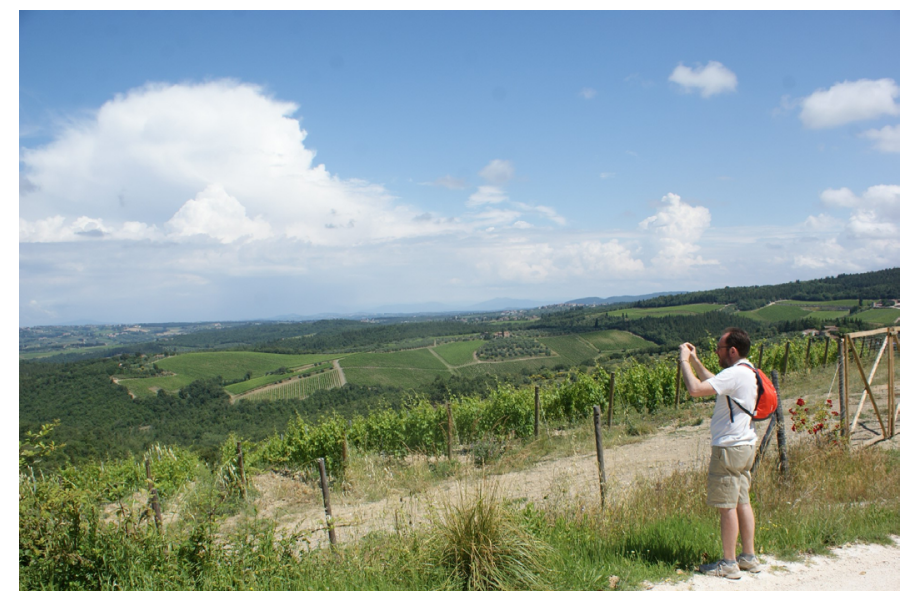

Figure 6. A man enjoying a view of the Chianti countryside- Italy

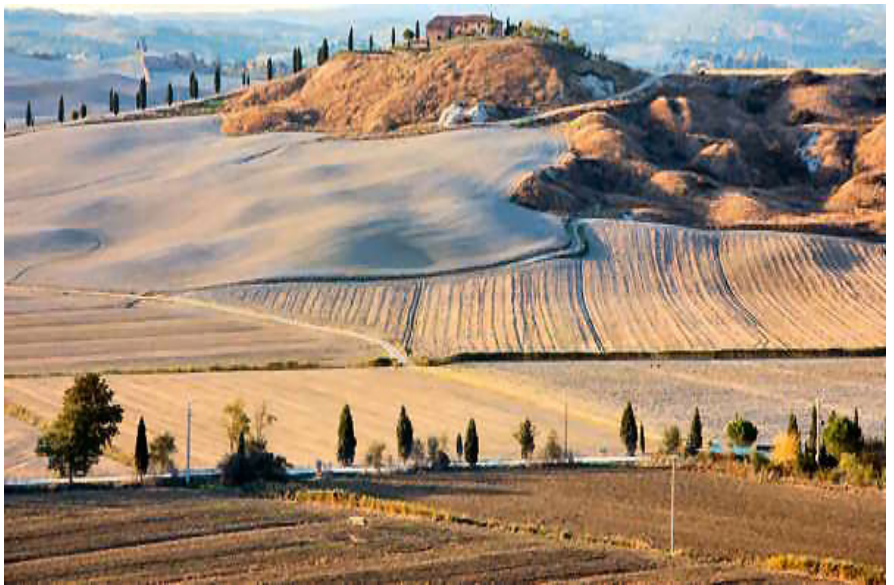

This image will vary depending on the perspective compared to an ordinary person, such as a poet, a ranger, an architect, a naturalist and so on.

According to scientists, the landscape is a combination of a set of objects and the relationships between them. According to historians, a landscape is the result of evolution of nature and human action In fact, when a building committee examines a building project in an area subject to landscape constraints it does not examine the plant or the calculations, but how the shape correlates with the appearance of the place where it will be built.

But there is an ultimate meaning from a symbolic point of view in which we can bring them back together: the landscape speaks of the person to person expression and reproduction of past and present cultural identity, either, in harmony or in contrast with each other. At the same time, the meaning of the landscape is produced in the encounter with the person who experiences, transforms and explores it with curiosity and or enchantment.

The basic concept is that the landscape does not exist as an objective reality: it is born of the sensory stimulus, it is an act of perception. The perception of the landscape is through space that represents the meeting point between me (the subject) and it (the landscape).

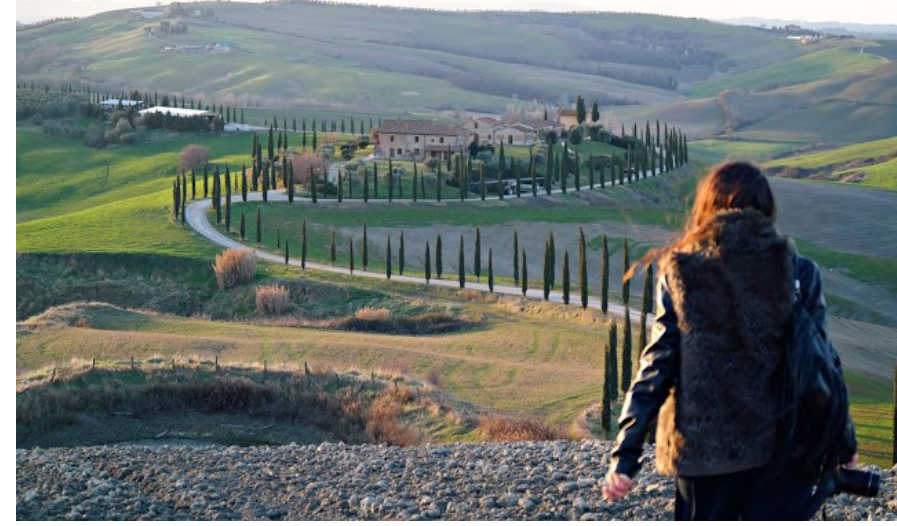

Figure 7. A woman enjoying a view of the Crete Senesi - Italy
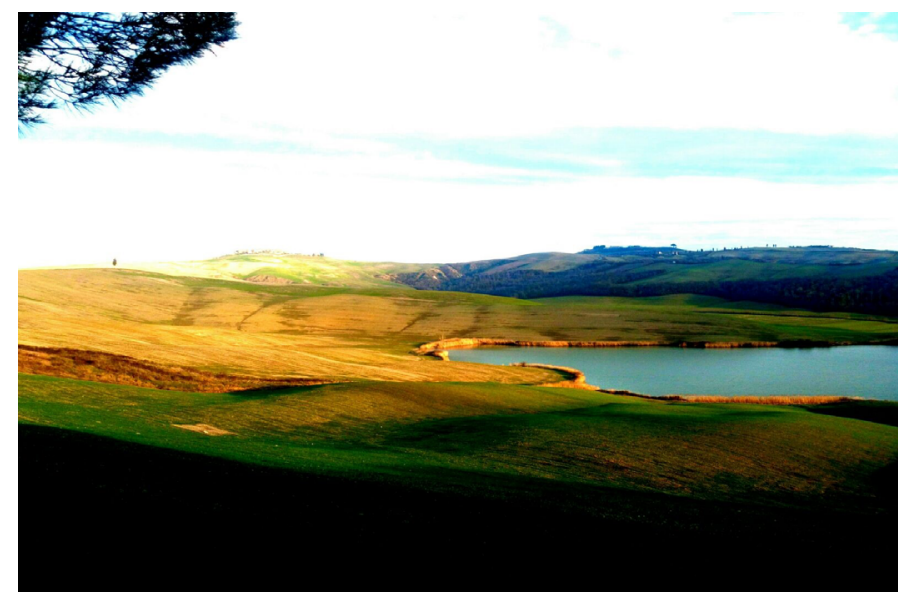

Figure 8,9. Views of Crete Senesi - Italy 
That space is a function of the perceiver's point of view, which is not only physical but also based on what the perceiver expects to see. The landscape thus has a subjective component: the landscape is born when someone sees it. So "we are our landscapes."

There are no landscapes without humans: a country or a terrain can exist without us, a landscape cannot exist without us. An example of how a landscape can change the perception of a terrain is with the Crete Senesi, a natural, wild but charming area south of Siena, in Tuscany, Italy: a horrible and depressed landscape in the past (low agricultural productivity, uninhabitable, impractical) which has become a beautiful landscape in the present (untouched natural landscape).

Conceptually speaking, a landscape is the opposite of a terrain with simply its collection of trees, grass, hills, and so on; it is something more. For example, maps fail to represent the scenery of a landscape.

Julius Verne describes in "Around the World in 80 Days", the spatialization of the world: in that case the subject is moving. Today, with the rise of globalization (since 1969, when two computers first communicated with each other), time and space are intertwined. On the web there is no longer the subject / object separation: the world economy operates at the same time in unison.

"Today, after more than a century of electronic technology, we have extended our central nervous system so that it has become a global embrace, abolishing the limits of space and time with regard to our planet."

(Herbert Marshall McLuhan)

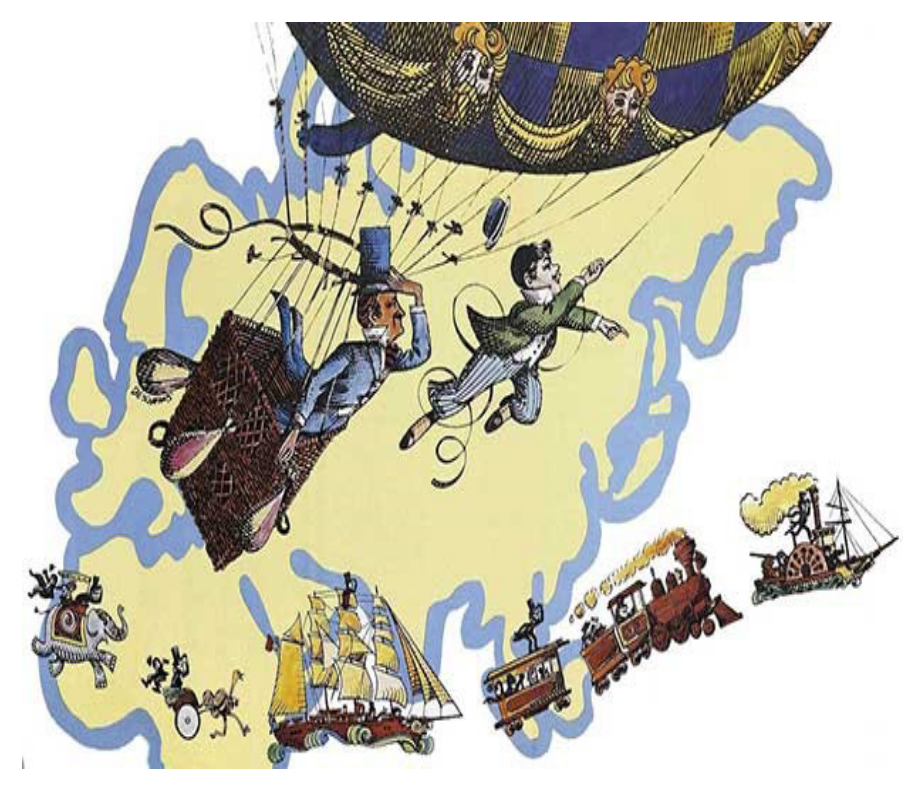

Figure 10. Julius Verne "Around the World in 80 Days"
So in today's world, distinguishing between space and time has little meaning: to appreciate the landscape as a subject, it is necessary to leave behind this modern concept and return to our natural, human experience of space and time. What models do we have to evaluate ourselves in the world? For this we need the landscape: the landscape can preserve our collective humanity.

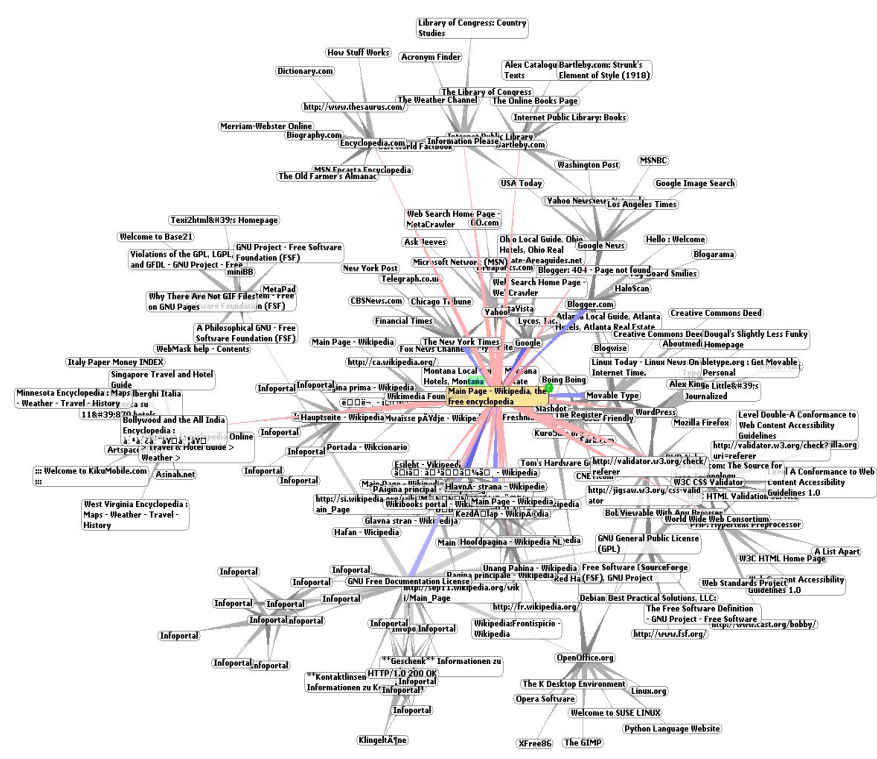

Figure 11. A graphic representation of the internet

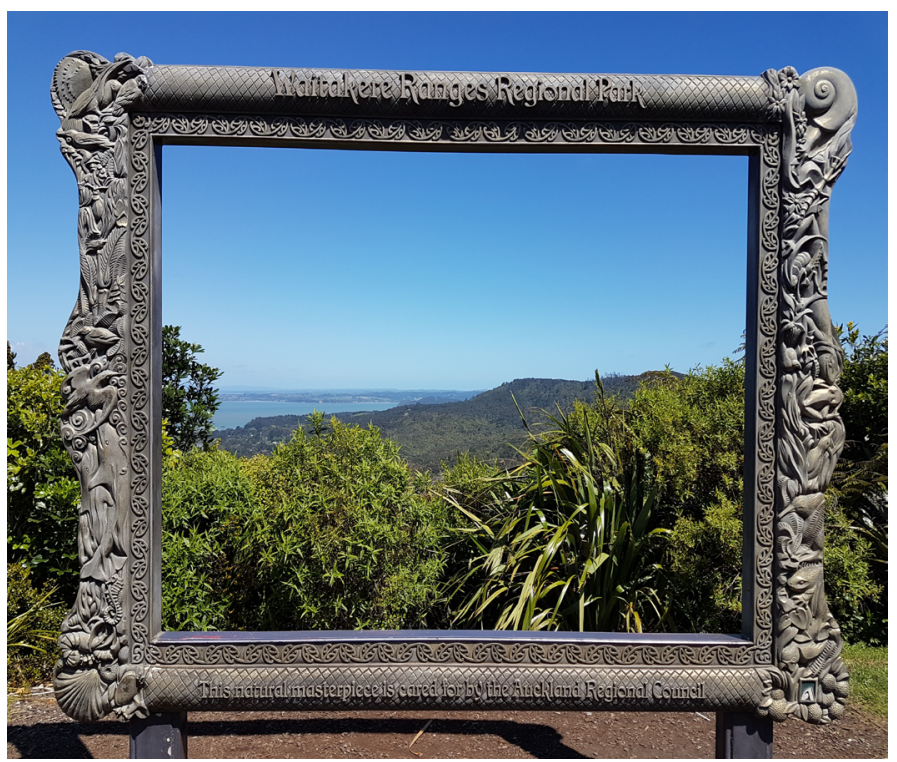

Figure 12. The landscape is a work of art (Waitakere - New Zealand) 


\section{Architecture and Engineering Volume 2 Issue 1}

The landscape is made up of places that "speak" to us about the way they were born, formed and layered. They communicate by revealing their identity or recognizing and interacting with other identities. There are two in landscape concept traditions:

1. The "cognitive landscape" understands landscapes as a set of "things," of tangible elements, and (possibly) the processes that formed them (traditionally called "substantialist").

2. The "narrative landscape" understands landscapes as a reflection of cultural processes (cultural tradition).

There are landscapes that many of us do not like (or even do not attract our attention) because we do not understand them; if we do not understand how they are formed, then tell us nothing. But if somebody explains this, then it is likely that those landscapes (such as artwork illustrated by an expert) peak our interest. History and social sciences on the one hand, natural sciences on the other, are the bodies of knowledge that help us understand landscapes, to make "friends" with us. So, landscapes (i.e., the terrain that evokes our emotions, feelings and sense of belonging) are not fixed; they can grow and multiply in our perception as we learn about them. And, our tendency to react strongly if we see "our landscapes" threatened will increase, even for landscapes in distant places, to which we affection.

\section{Statements about the landscape}

The land belongs to its owners, but the landscape belongs to those who can appreciate it.
The landscape is the most beautiful energy that you can get for nothing.

A landscape is the magic of a sunset, the bridge that brings together people and nature.

The landscape is not only the result of the relationship between people and environment: it is the best indicator of health of this relationship.

The landscape is that which is around us (that is, after all, "the country"), and arouses in us emotions, feelings, and in particular a sense of belonging.

Do not govern the landscape but the human behavior acting upon it.

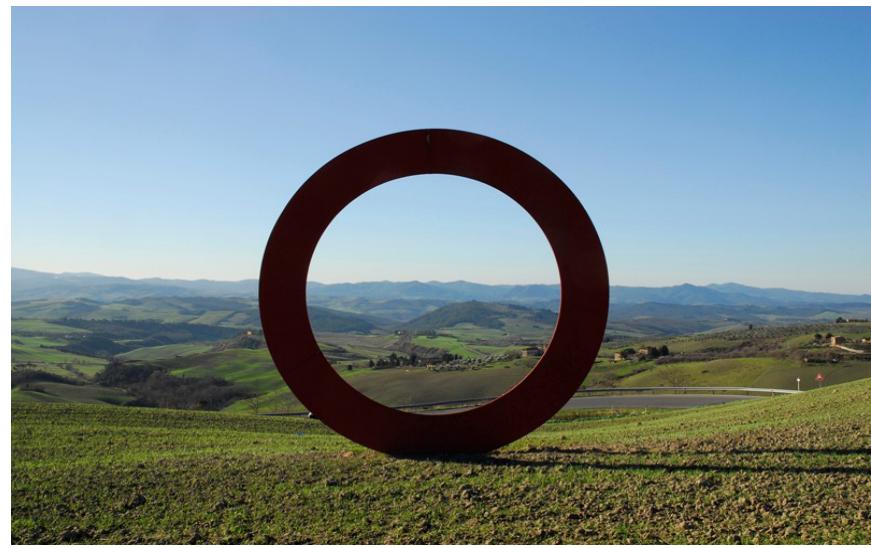

Figure 14. The landscape is a work of art (Volterra - Italy)

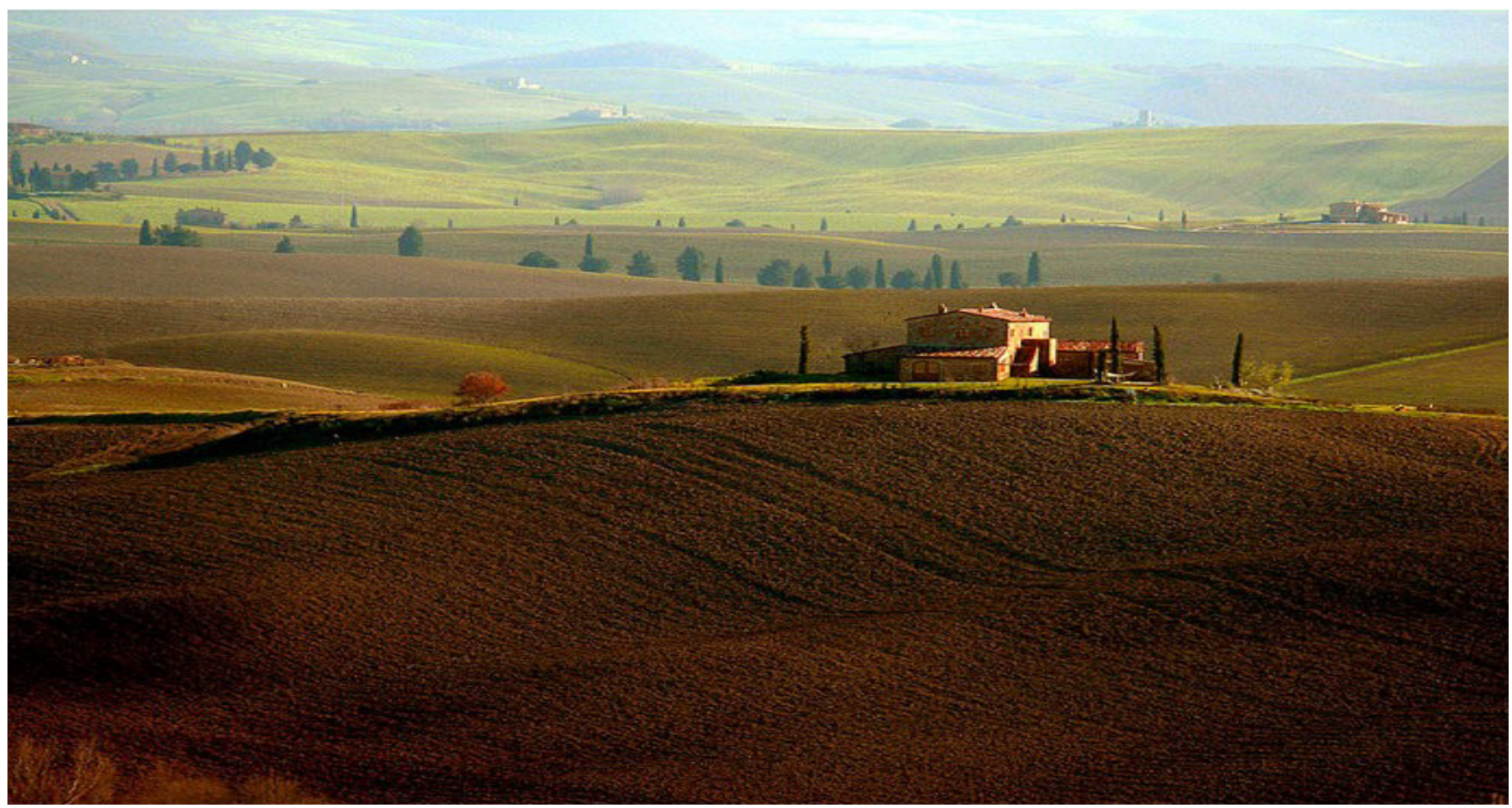

Figure 13. A view of Val d'Orcia - Italy 
Because the novelty of the world today is this: that more and more landscapes are "ours" because we are increasingly mobile and "possess" many more landscapes than past generations.

Every place has a landscape and every landscape takes on values.

The landscape and art are closely related entities because in the landscape there is nature, and art is the right arm of nature. To this a landscape is like a picture that is a work of art.

\section{Cultural approach to the landscape}

The image of nature and landscapes owes much to the aesthetic representations derived from paintings, travel accounts and postcards to the extent that we think about the landscape as a cultural construction. This landscape-image relationship over time refers to the cultural construction of the landscape and the false choice between the "authentic" and the "inauthentic:" the authentic landscape is an invention or better, a cultural construction. Yet this false choice has determined, and still determines, the aesthetic appreciation of the landscape, its recognition as something beautiful and worthy of being observed.

The recognition of what is beautiful finds its aesthetic explanation, for example, with Sienese painters and with photographers who have "frozen" the landscape of the Crete and Chianti to make them one of the most favorite and desired images both locally and worldwide. Photographs of green pastures, sunflower fields, the hay bale decorating the barren hills, cypresses as the only shrub that stand out amid the arid expanses, are very well known in the tourist imagination. Contemplation, for that matter, is the first act of the foundation of the landscape: it exists through our eyes (although there is also space), and ethnological analysis can focus on the ways in which people who relate to the landscape tend to mold it, define it, build it, and through these practices, define their own identity.

Appropriating the places where people live provides the opportunity to tame the landscape, turning it into something familiar, something to recognize creating a feeling of "home."

The urbanite looks at the landscape with a desire to go to live in the country, to return to nature, as if they had lost a part of their roots in the frantic city life. The lifestyle is slower, the shops are very welcoming, the shopkeepers are more friendly. Everything is known by everyone, you can count on the things that you see, the neighbor is a friend, respects you, and will not ignore you as in the city life. It's very different than living in a condo and shopping at the supermarket. Those who decide to live in the country recover serenity from their daily life spent in the car half the day taking their children to school or the gym or going to the market. For those reasons or even for economic ones, people who live in city make the trip out of town for the weekend or go in a farm to curl up in nature.

The modern way to experience the countryside by an urbanite produces environmental changes to the land: the country takes all the comforts of the city away, so urbanites build garages, perimeter walls, gates. The urbanite who goes to live in the country does not like the shit of the hens, the stench, or the mud. The urbanite has an aesthetic approach to life, while the farmer has a utilitarian approach to life.

For farmers, the beauty is utilitarian: an ox, a sunset, a tree are beautiful if they are useful to them. An uncultivated field is ugly to the farmer because BEAUTY = PROFIT. As for the urbanite, an uncultivated field can be beautiful. If an olive tree is not pruned, it's useless for the farmer, while it may be pretty for the urbanite. So, there are different perspectives of the countryside and the landscape:

- For those who go to live in the country ---> romantic vision, need for city services, lawn;

- $\quad$ For those who have always lived in the country ---> economic and utilitarian perspective. LANDSCAPE $==$ SURVIVAL

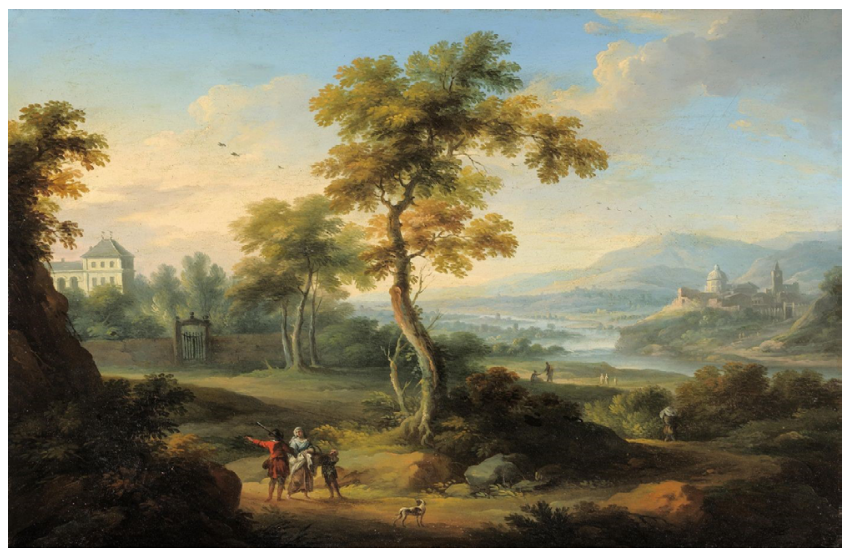

Figure 16. The romantic painter's conception of landscape

Figure 15. The country peoples' conception of landscape (1908- Italy) 


\section{Read and listen to the landscape}

Perception is a simultaneous phenomenon that recognizes the landscape in continuous harmony with the model of holistic continuity of Gestalt:

The whole is more than the sum of its individual parts (basic Gestalt principle)

Walking through a terrain you will find invisible landscapes made of scents and sounds that interact with the person looking at the landscape. There is an order in the landscape, a grammar similar to a musical score, a landscape's music or "Soundscape." You can find this musical symphony anywhere in a landscape. If you shoot a $360^{\circ}$ photo of a landscape, there are repetitions and sequences to the different parts of the landscape: combining a sound to every part produces music, music specific and exclusive to that location.

We must avoid the urbanite's experience of estrangement from the countryside that leads them to look for opportunities to exploit landscapes rather than live in peace and harmony with the environment. Care of the landscape requires integration between people and the environment, an approach that bridges the gap between us humans as subjects observing the nature that surrounds us..

We can only know the landscape by going through it.

Even if a landscape has been altered as a result of social and cultural norms or human use, we have to walk through the landscape rather than watch it from the outside in order to understand it. The correct way to learn about the landscape is to spend adequate time, to go slowly, and to be far from the frenetic rhythm of daily life. The best approach to understanding the landscape is to follow your curiosity as a process of discovery rather than being confined to the constraints of the goals to be achieved pacing quickly through its paths.

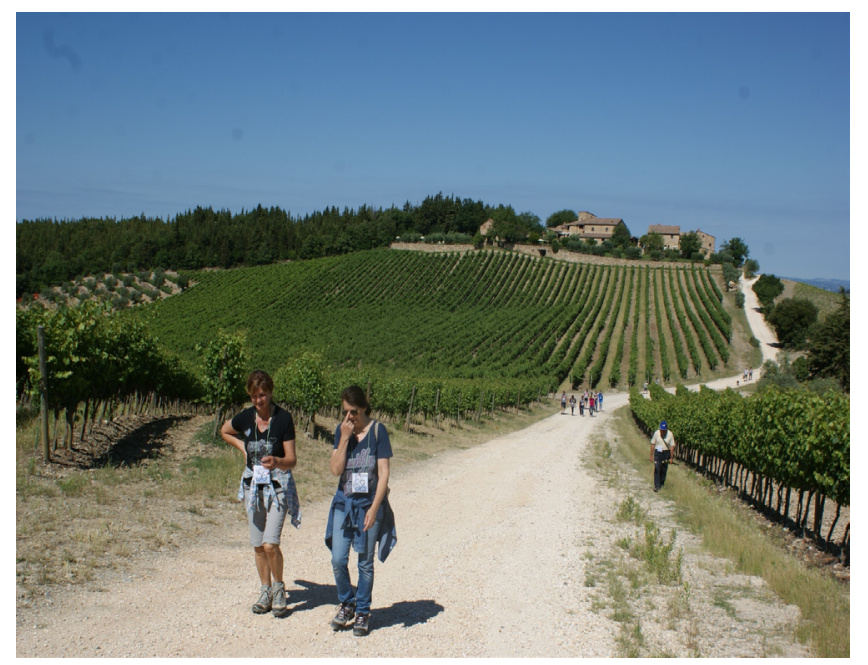

Figure 17. Walking along the Chianti area (Italy)
This is the delightful mobile landscape in which we move slowly along to perceive its fine textures. When our body is moving slowly in space we understand the culture and the meanings of the elements of the landscape that we can see; these give us a sense of pleasure and of comfort.. We experience the enjoyment of the landscape when we rediscover the integration of space and time. In view of vulnerability of landscapes and the risk factors that effect the space and time balance, we must safeguard them from interventions and restoration.

\section{Economy and landscape}

The landscape is now considered so valuable that it cannot be reproduced; it functions as an economic driver of an area and production systems connected to it, and is threatened by the globalization of markets and the loss of competitiveness of large production areas. From this point of view, not only are the roles of diversity and historical identity competitive factors, but also the restoration and design of new landscapes can combine qualitative and production goals.

The distinctive landscape is not the result of any particular agriculture, nor a generic idea of a "return to nature" or "abandonment of nature;" these are not effective ways to achieve the sustainability of development. It is common to confuse the landscape with nature conservation, while the advantage of economic development, derives from the value of the landscape, this does not take responsibility for its quality into account. This should be a smart balance between land management and a beautiful landscape. Because a beautiful landscape is the result of good care of the land rather it its image, we can instantly tell if a landscape is beautiful or ugly standing in front of its panorama: the sense of beauty is the result of a harmony that originates from the way the land is used.

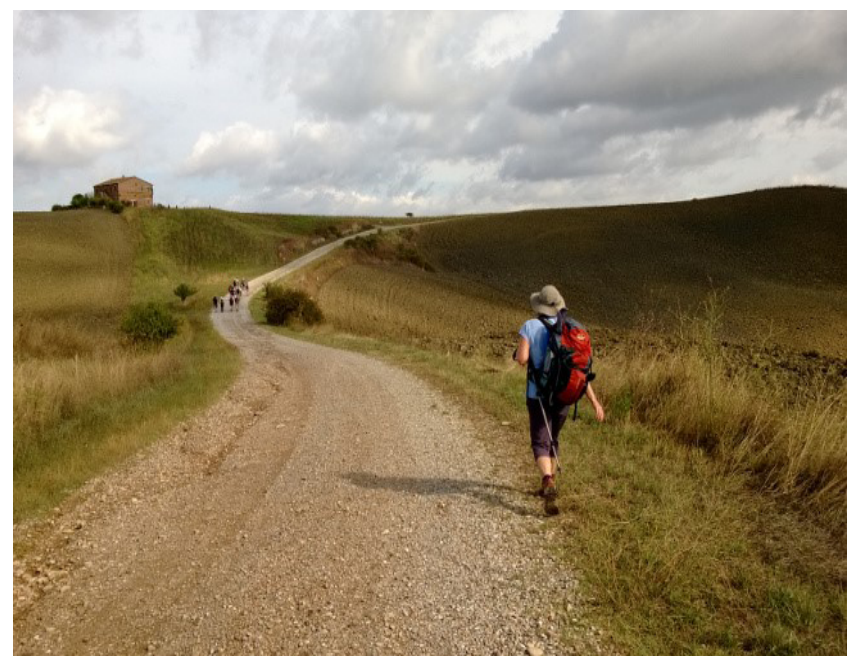

Figure 18. Walking along the Crete Senesi area (Italy) 


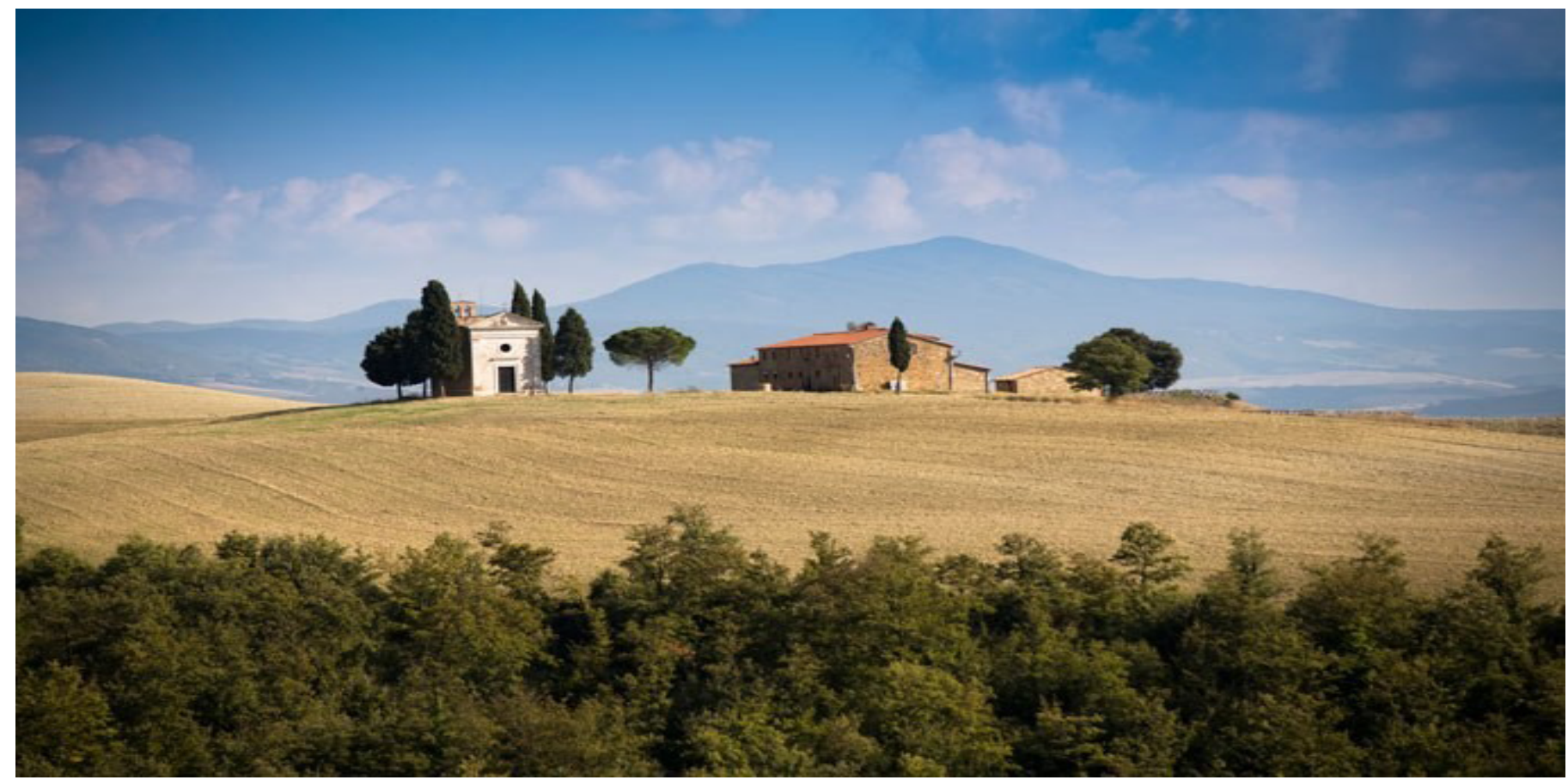

Figure 19. Vitaleta chapel (San Quirico d'Orcia-Tuscany- Italy)

A good landscape which identifies a location, is a need for all of us. A good landscape produces a sense of well-being, a bad landscape produces malaise. The landscape also affects our actions and our choices: wine from a nice area can be considered better than one from a place that is not considered a quality location; a degraded landscape reduces destructive inhibitions and contributes to social decay and crime (the theory of the broken window).

A good landscape also has great economic importance. In Italy tourism produces about $30 \%$ of the gross national product, but it would not exist if there was no tourism for beautiful and interesting places to go and see. When we search for the house we wish for, if we can afford a home "with view," this costs significantly more than a comparable house that overlooks a courtyard or on a busy road. The same situation applies to hotels: rooms with views cost more than those with no views.

The fact that the beauty of a landscape is a need and has economic value, its cost is now under study. For example, Francesco Marangon and Tiziano Tempesta, agricultural economists have estimated the economic value of the beauty of a vineyard to be around one thousand euro per hectare (Marangon F., T. Storm, The impact on the landscape of the hilly wine-growing. An economic assessment of Friuli DOC zone - Venezia Giulia.

What then is the value of the beauty of a landscape? How much is the value of a view, the view from an exact point in the terrain? The subject is fascinating: surely the real estate market takes this into account with its economic guidelines. This point is a challenge, which is to be able to provide an exact economic value to a specific landscape. But the overall question is: what is the value of beauty?

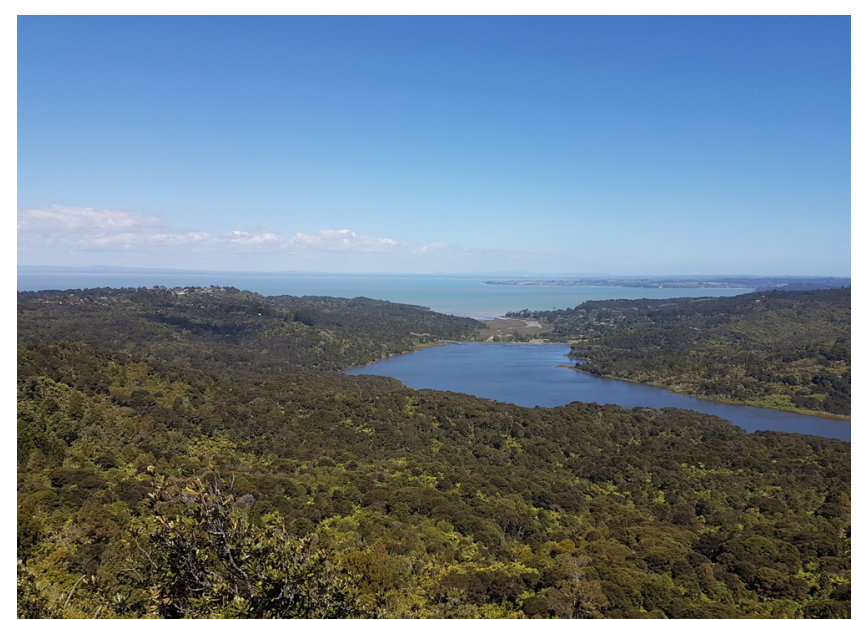

Figure 20. A very natural landscape (Waitakere - New Zealand)

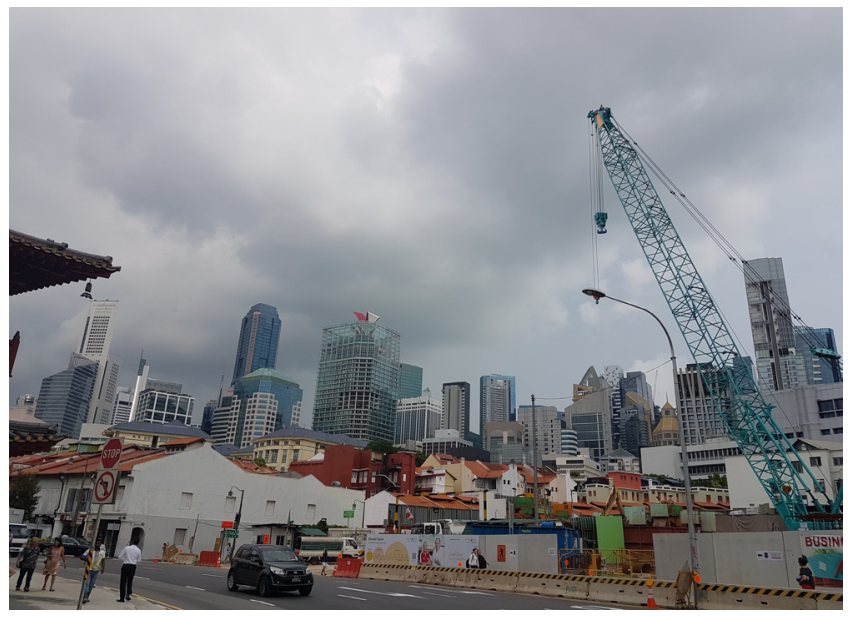

Figure 21. A very constructed landscape (Chinatown - Singapore) 


\section{Architecture and Engineering Volume 2 Issue 1}

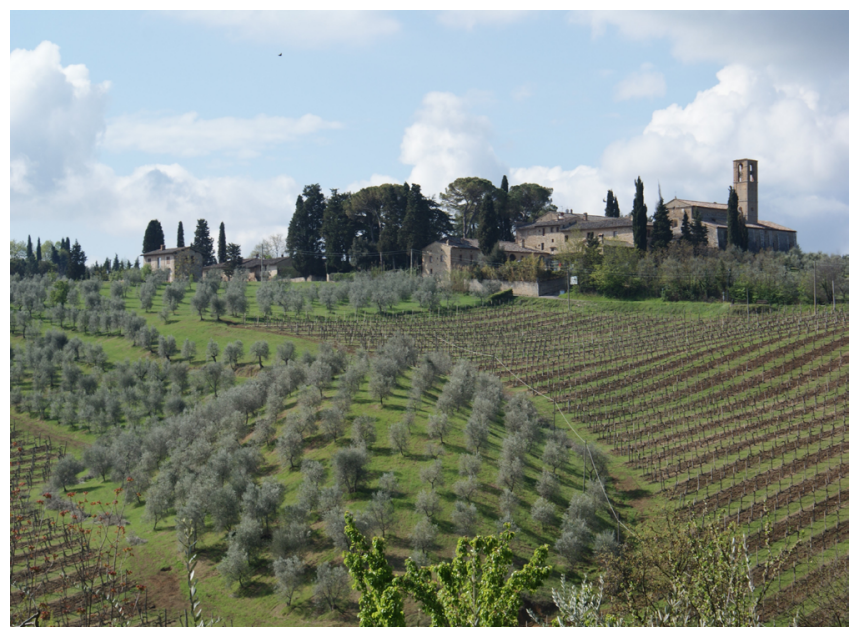

Figure 22. A good countryside landscape (Monteoliveto-Tuscany-Italy)

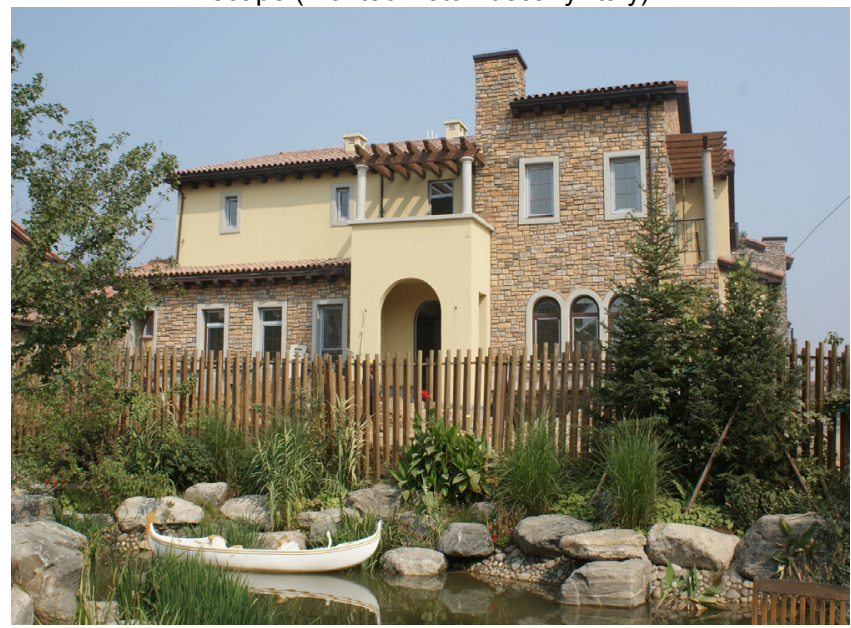

Figure 24. A new Italian style villa Bramasolo (Bejing-China)

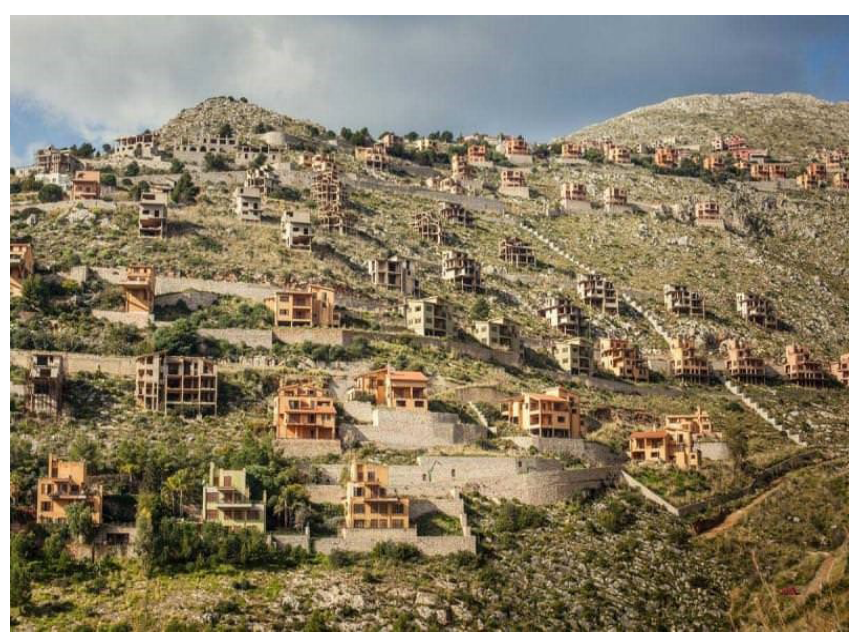

Figure 23. A bad countryside landscape (Mondello-Sicily-Italy)

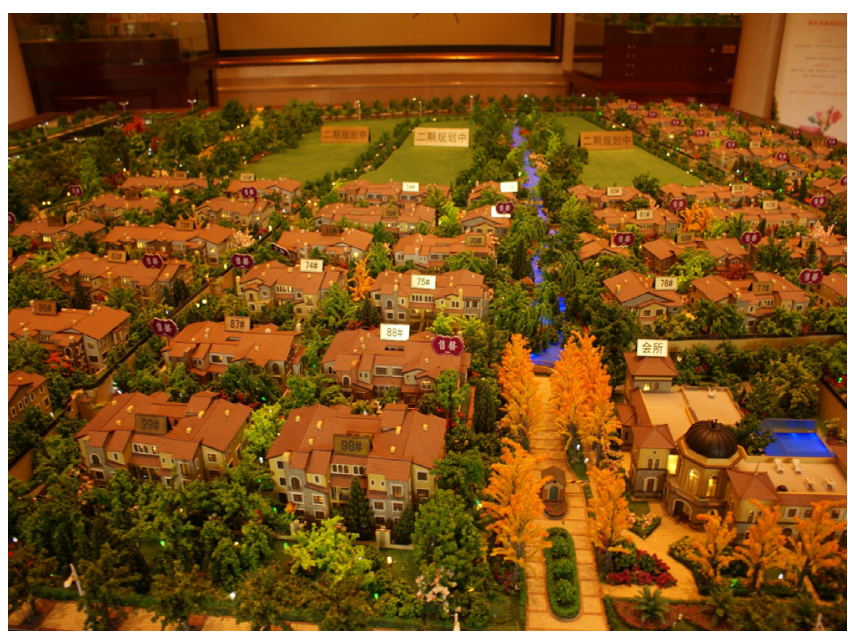

Figure 25. The new Italian style village Bramasolo (Bejing-China)

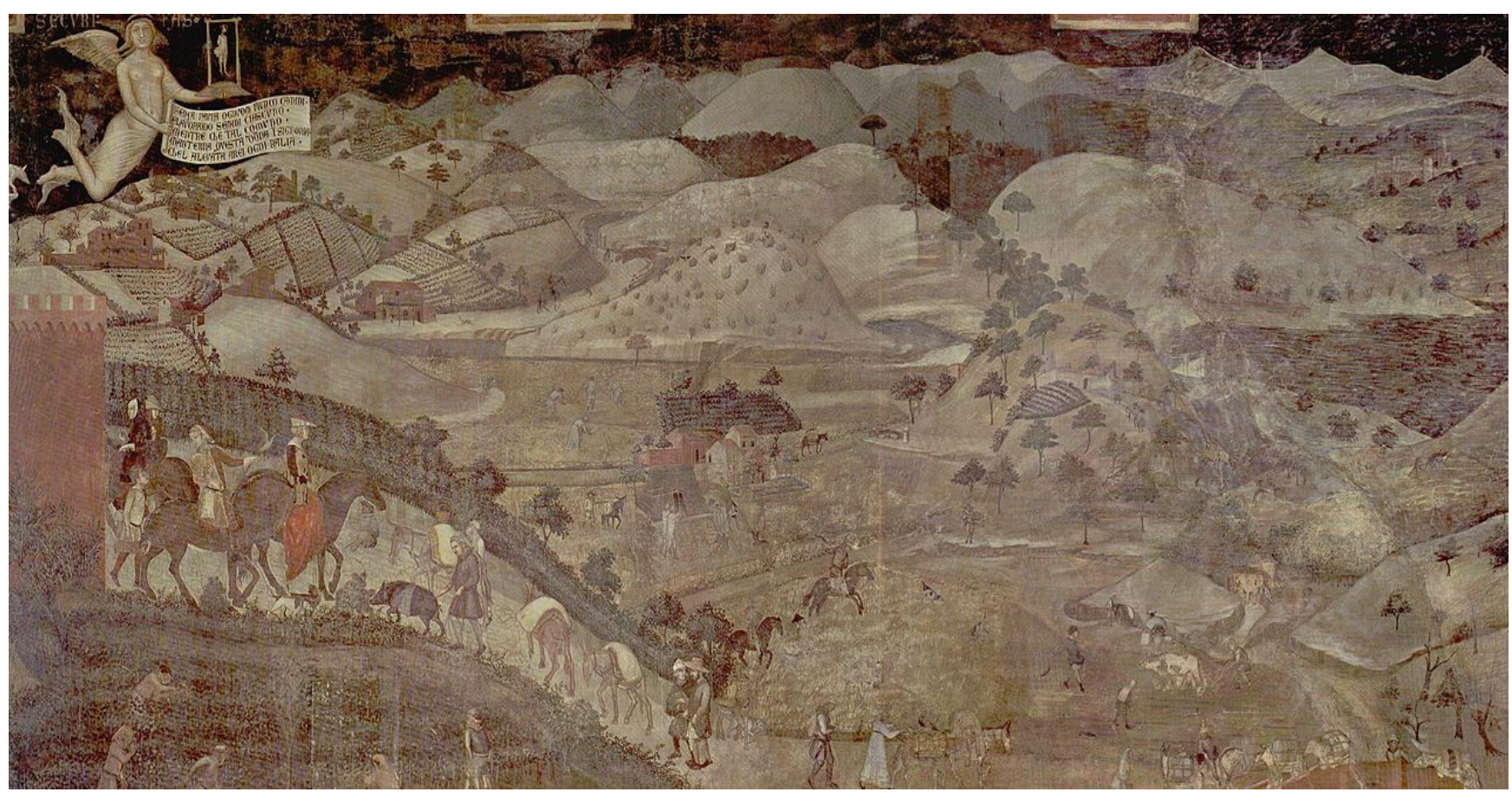

Figure 26. Ambrogio Lorenzetti: "Effetti del Buon Governo in campagna”, 1338-1339 (Sala della Pace, Palazzo Pubblico, Siena-Italy) 


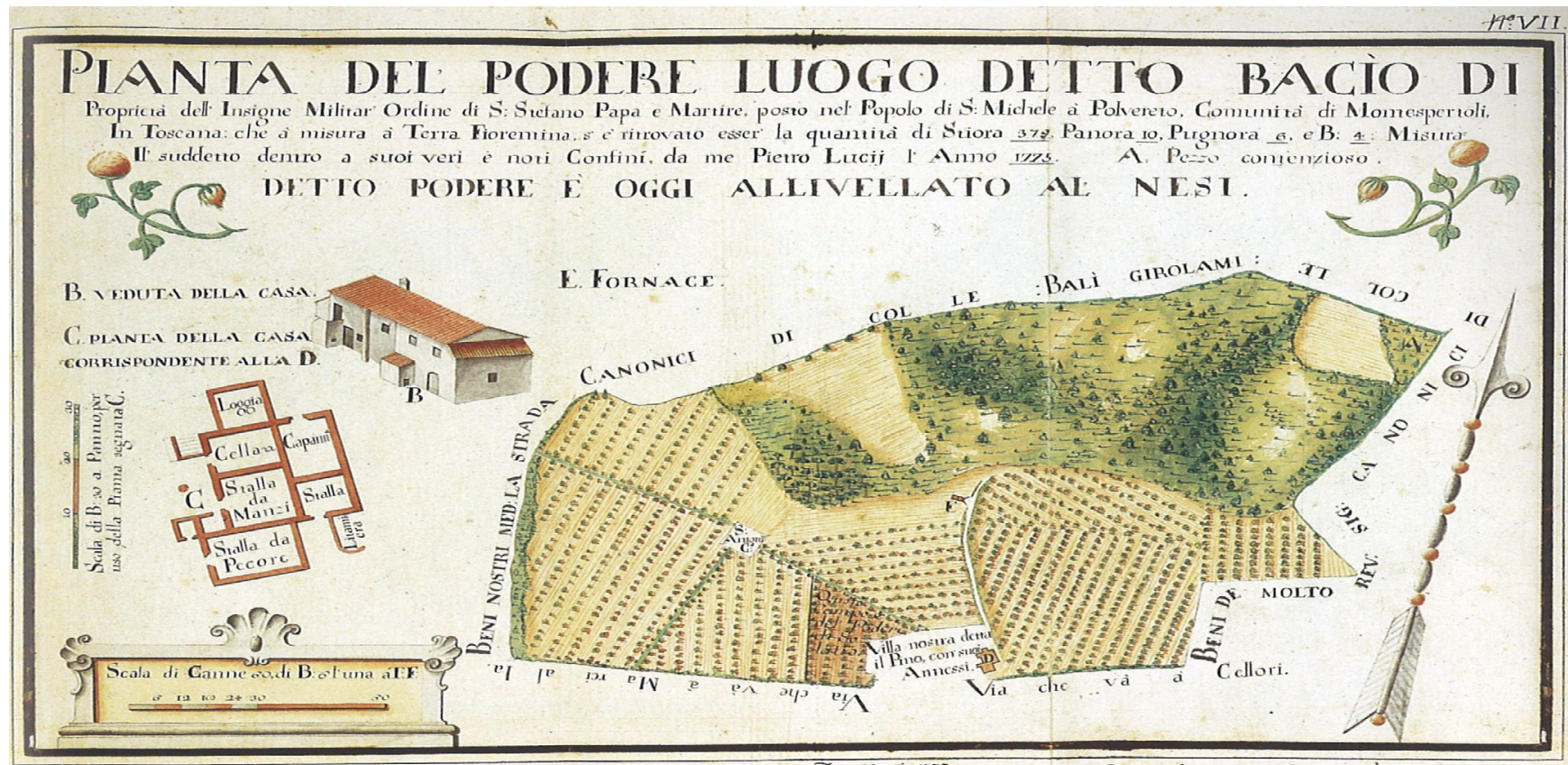

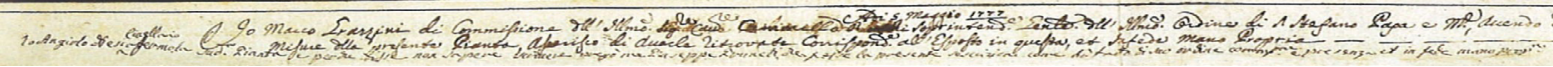

Figure 27. Typical "cabreo", an agricoltural map of 1775 (Monterspertoli, Tuscany-Italy)

The landscape has already become a marketing tool in the world: for example in Beijing (China) a "Tuscan village" was rebuilt to sell new villas to rich Chinese people who lives in the polluted capital, using the Italian style, and the charm of the beautiful Tuscan landscape (Italian). On a sign at the entrance of the village it is written:

"Italian lifestyle, romantic and comfortable lifestyle, full of beautiful sunshine, sunflowers, beautiful peace, brilliant Italian temperament, an optimistic desire to sunlight."

\section{Evolution of the landscape}

The landscape may seem eternal, unchanging in its vastness and its characteristics but in reality landscapes change like a huge living being: the landscape changes with seasonal variations (natural reasons) and with changes produced by human activity (artificial reasons). Both of these causes change the fields crops (seasonality and agricultural production cycles) and introduce new elements (modeling of the terrain, buildings). The feeling of "permanent variability" is the great charm of the landscape.

We, living mainly in cities, are not aware of the transformations of the streets, the shops, the signs, and other urban indicators of change because we have adapted to the reality that the city should transform itself. The natural or countryside landscape is assumed to be unchangeable and would always remain the same because it constitutes our "cultural stillness" in which to entrust our certainties. In fact, the landscape changes, like us, like our lives, like our society.

For centuries the landscape didn't have great changes: little changes in cities, little changes in countryside until the second world war.

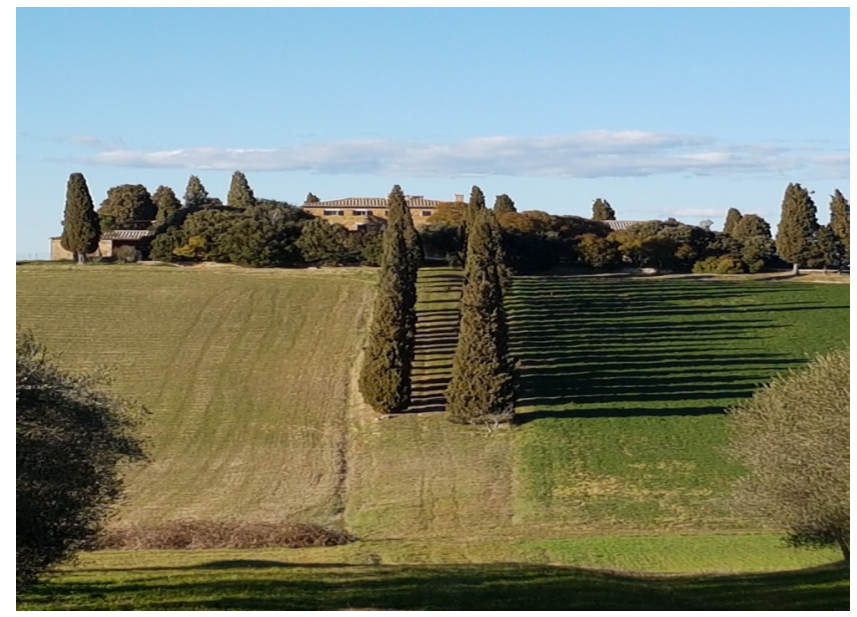

Figure 28. The seasonal changes of the landscape (Villa near San Quirico d'Orcia, Gladiator movie set, Tuscany-Italy)

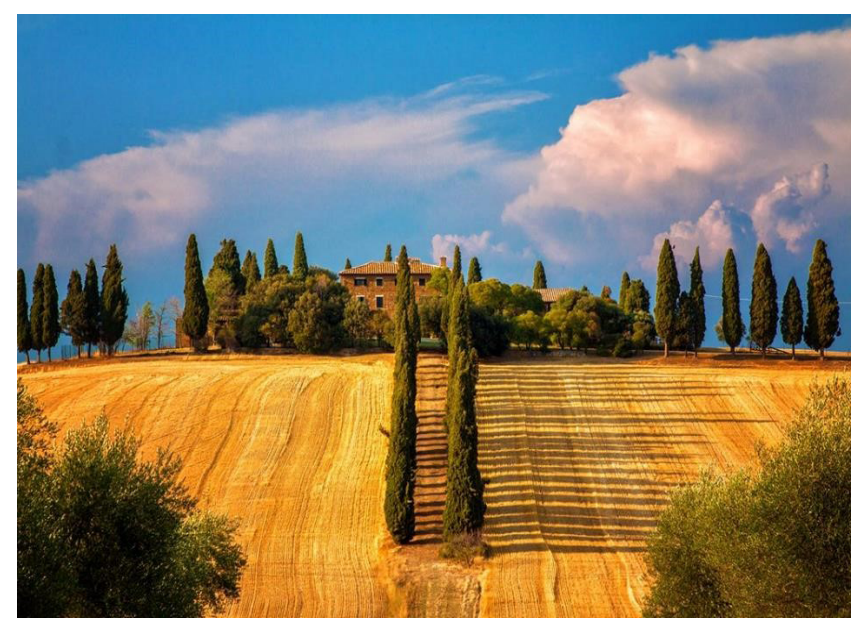

Figure 29. The seasonal changes of the landscape (Villa near San Quirico d'Orcia, Gladiator movie set, Tuscany-Italy) 
The crisis and disintegration of sharecropping (which exploded at the end of the last war for reasons both economic and social) was born along with landscapes covered by urbanization, the abandonment of the countryside or planned reforestation. New rural landscapes, much more uniform than the old ones, were products of the market conversion resulting from the reorganization of the economic system now based on crop specialization, automation, and large corporations or directly managed by small business owners. This is at the cost of a large number of farmhouses and villas that were almost always converted to non-agricultural use or not infrequently left in a state of neglect.

These aerial images of the camps in 1954 shows very jagged small plots and with almost complete exploitation of the soil. For centuries the landscape had the same image. After almost 60 years, an aerial photo in 2013 of the same place, shows that the land is unrecognizable: crops changed, there are few but extended plots, and wooded areas are enhanced. The end of sharecropping and the depopulation of the countryside along with automation have led to specialization of the utility of the land. These changes in land use and thus of the landscape are continuous and incessant because they are related to the use that people make, which in turn change in response to changing society.

In Italy, for example, in 94 years (1911 to 2005) we have witnessed:

- Agricultural land was reduced from 22 to 12 mlnha
- The wood is increased from 5 to $10 \mathrm{mlnha}$

- The total population increased from $35 \mathrm{mln}$ to $60 \mathrm{mln}$

- The population of the country has decreased by 15 million ( $43 \%$ of 35 million) to 4 million ( $6 \%$ of 60 million).

- From 1990 to 2005, the urbanization in Italy has eroded agricultural land to 8,200 ha / year.

- From 1954 to 2003 Florence has doubled the urban area but the population has remained the same.

How can we take care of the terrain and therefore the landscape? The approach to caring for agricultural terrain has become almost exclusively economic, which for centuries has consolidated the image of a rural landscape to be very small (the farmer always had the hoe behind him). This is food for thought for further investigation on the best development of the land.

\section{Examples of mistakes in the landscape}

The landscape evolution is a long process which needs a right time according to the entity of the change.

In fact when new developments of villages in the countryside are planned and realized, they raise a lot of discussions and debates that sometime take on very hard tone because that plan change quickly the cultural identity of the place.
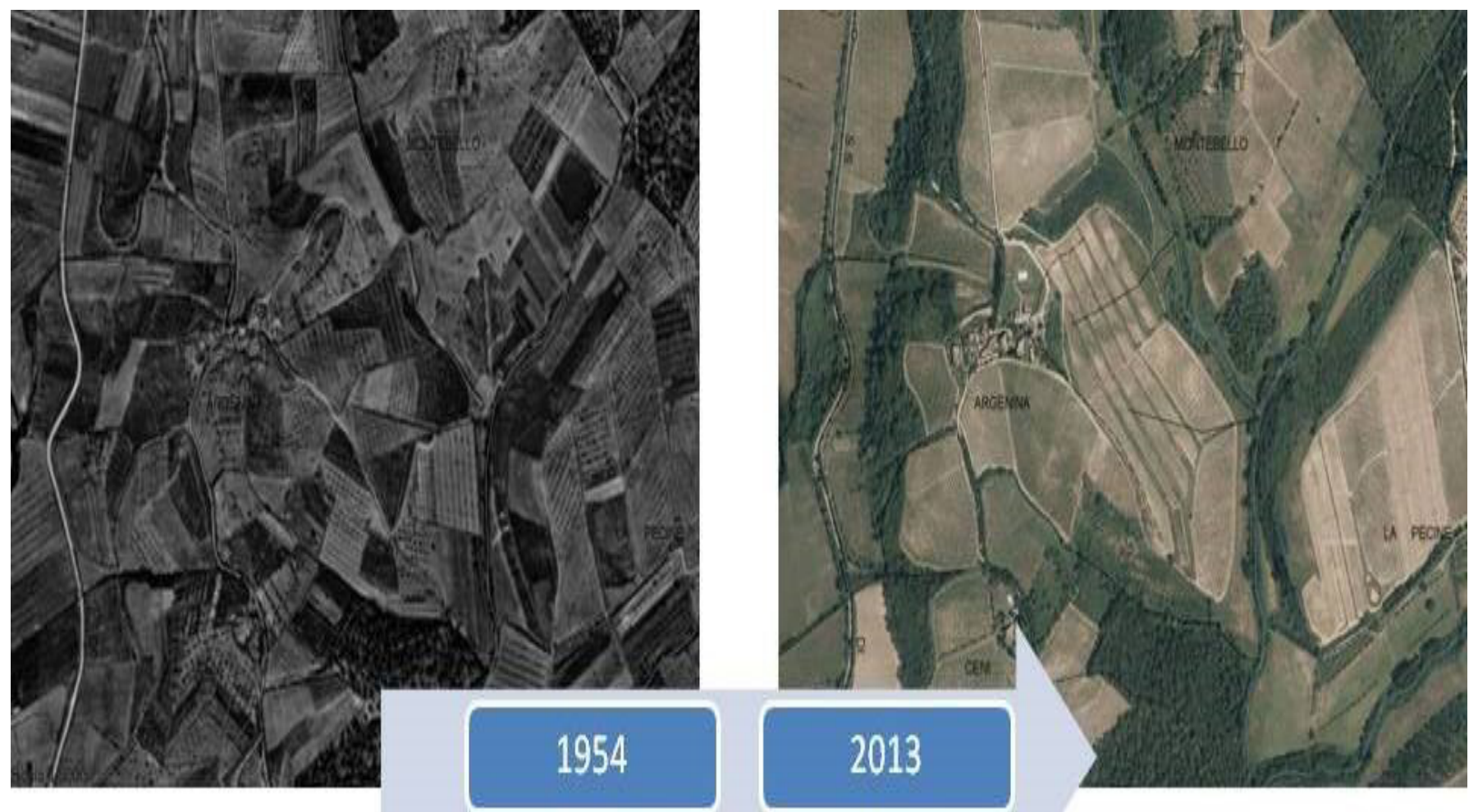

Figure 30. The impressive changes of the landscape at Argenina (Chianti area-Tuscany-Italy) 


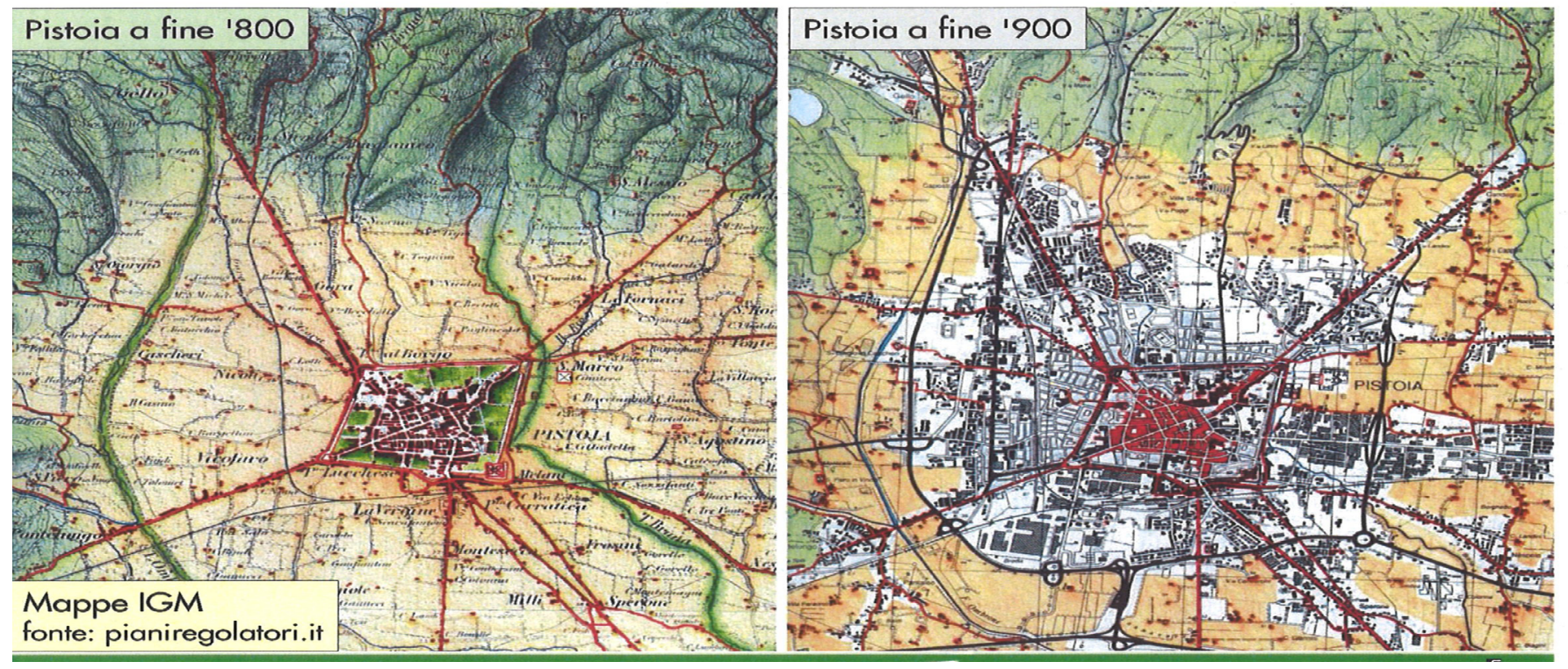

Figure 31. Development of the city of Pistoia - end 1800 end 1900 (Pistoia-Tuscany-Italy)

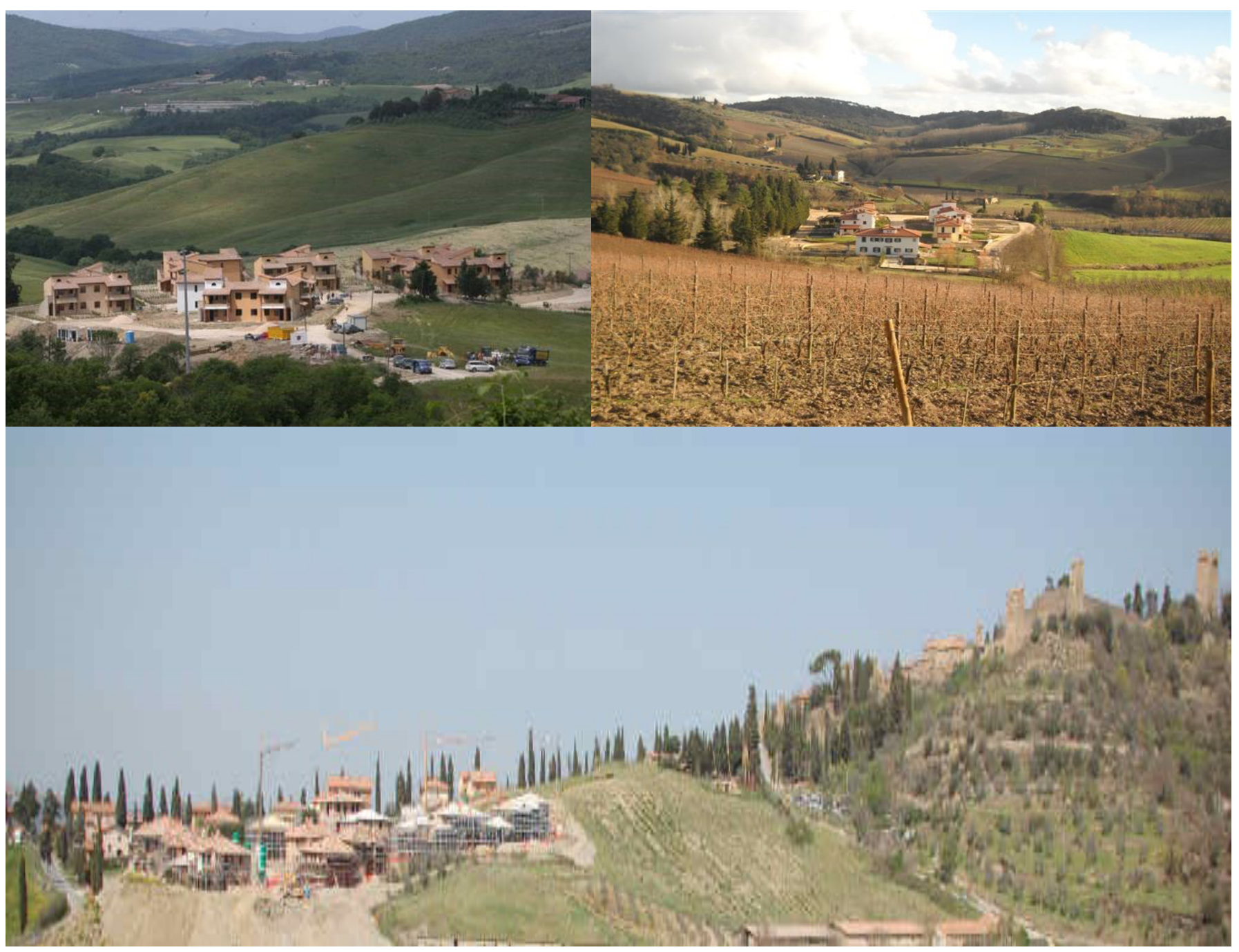

Figure 32, 33, 34. Cases of villages developments on hill positions (Tuscany-Italy) 


\section{Architecture and Engineering Volume 2 Issue 1}
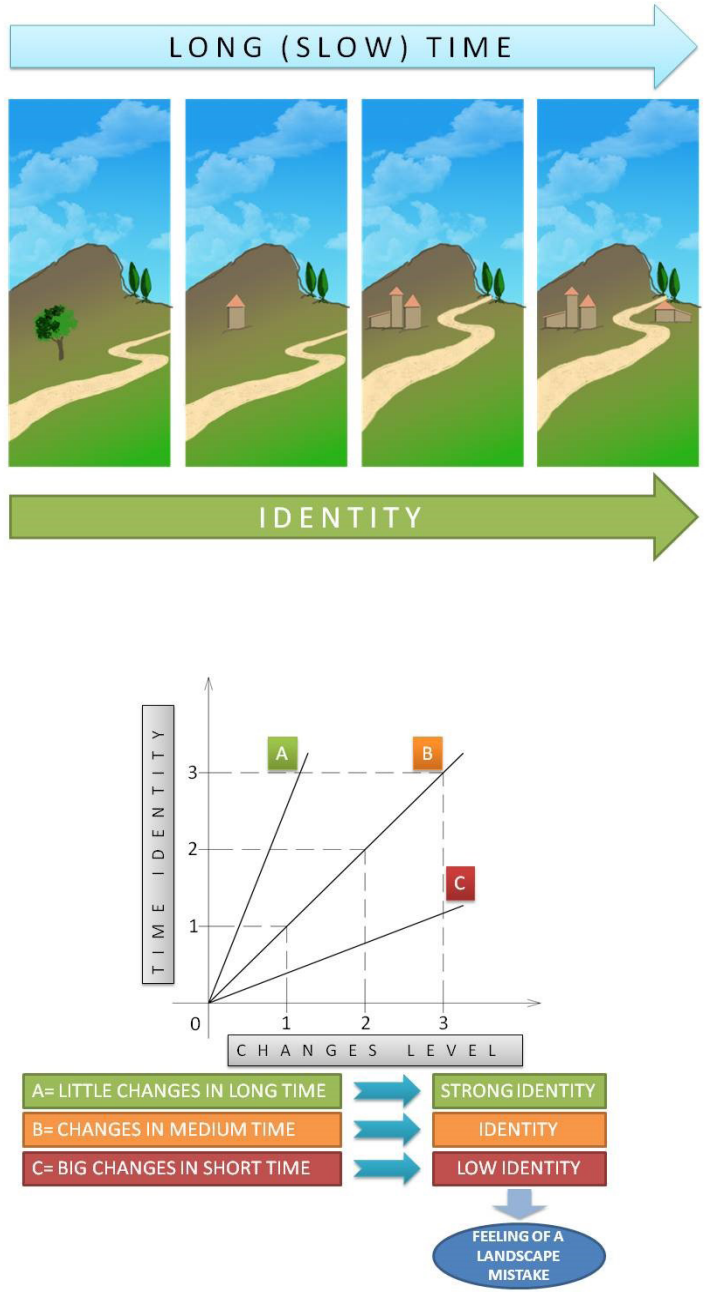
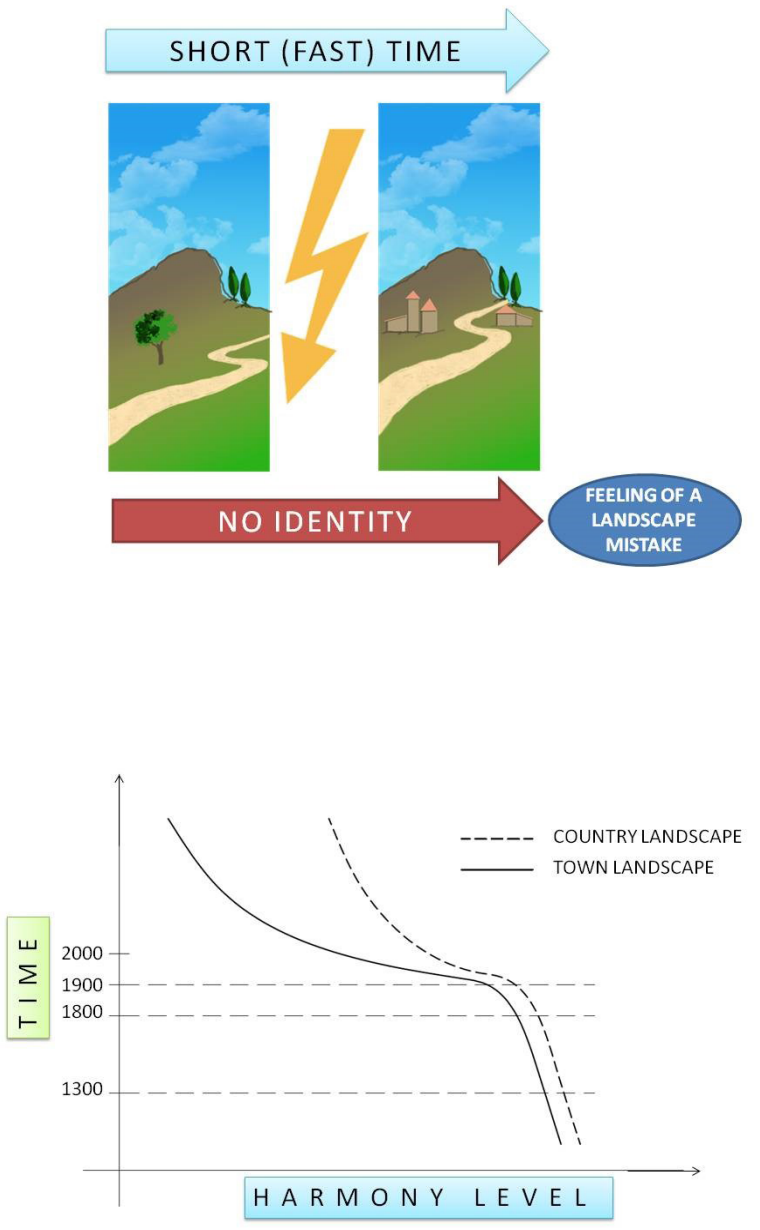

Figure 35. Identity and changes in time
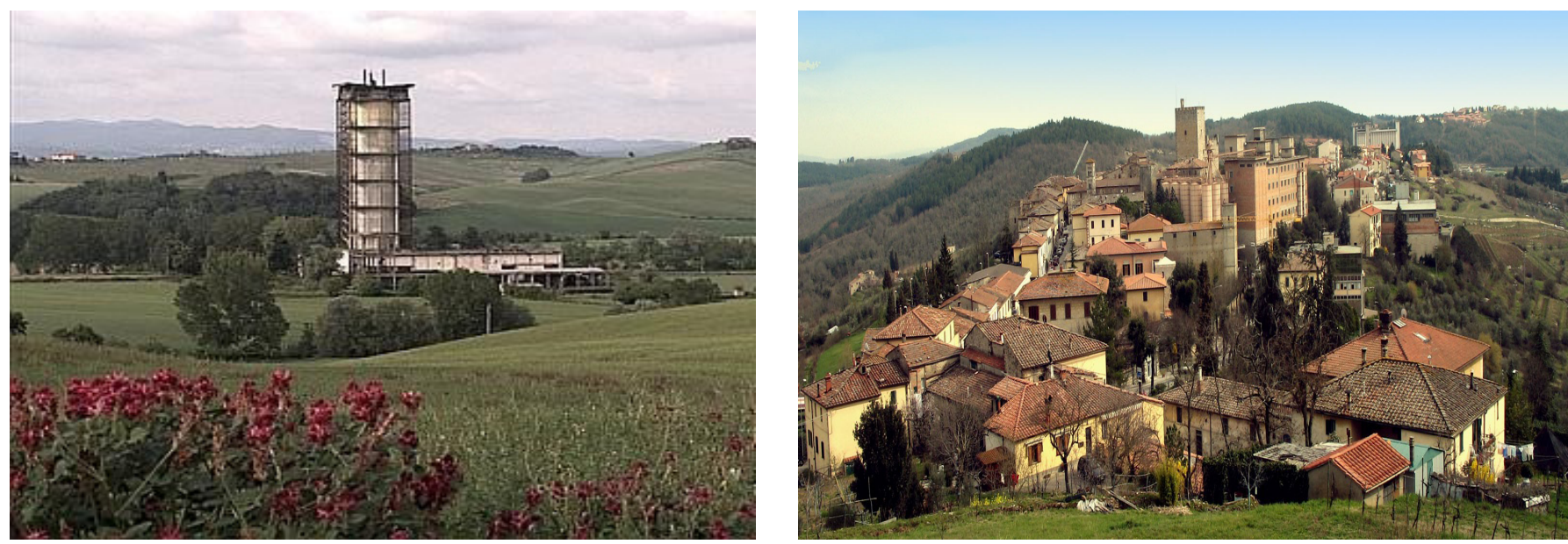

Figure 36, 37. Cases of industrial buildings without any connection with the landscape: they could be anywhere and everywhere in towns or industrial areas (Tuscany-Italy) 

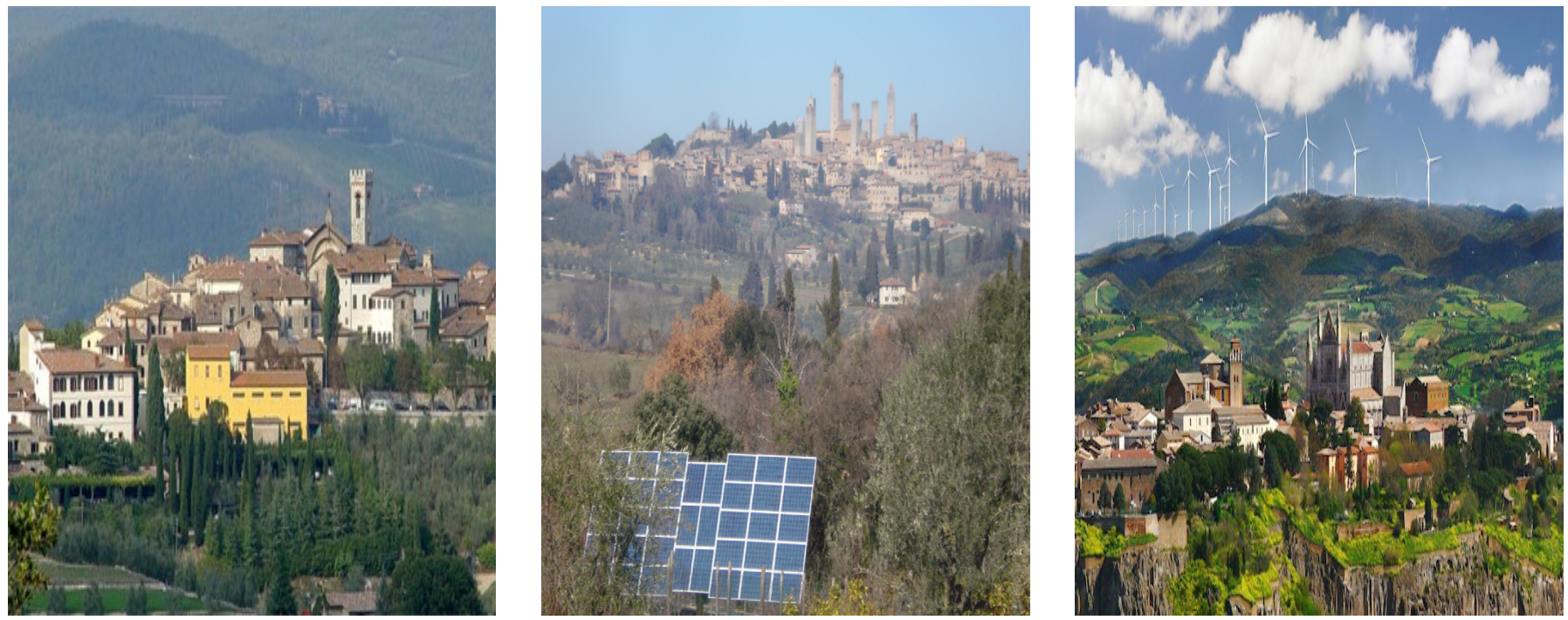

Figure 38, 39, 40. A wrong color of a single building can destroy the beauty of a landscape-Solar panels and wind turbines can't be located in the middle of a natural landscape but are in direct contact with the existing constructions (Tuscany-Italy)
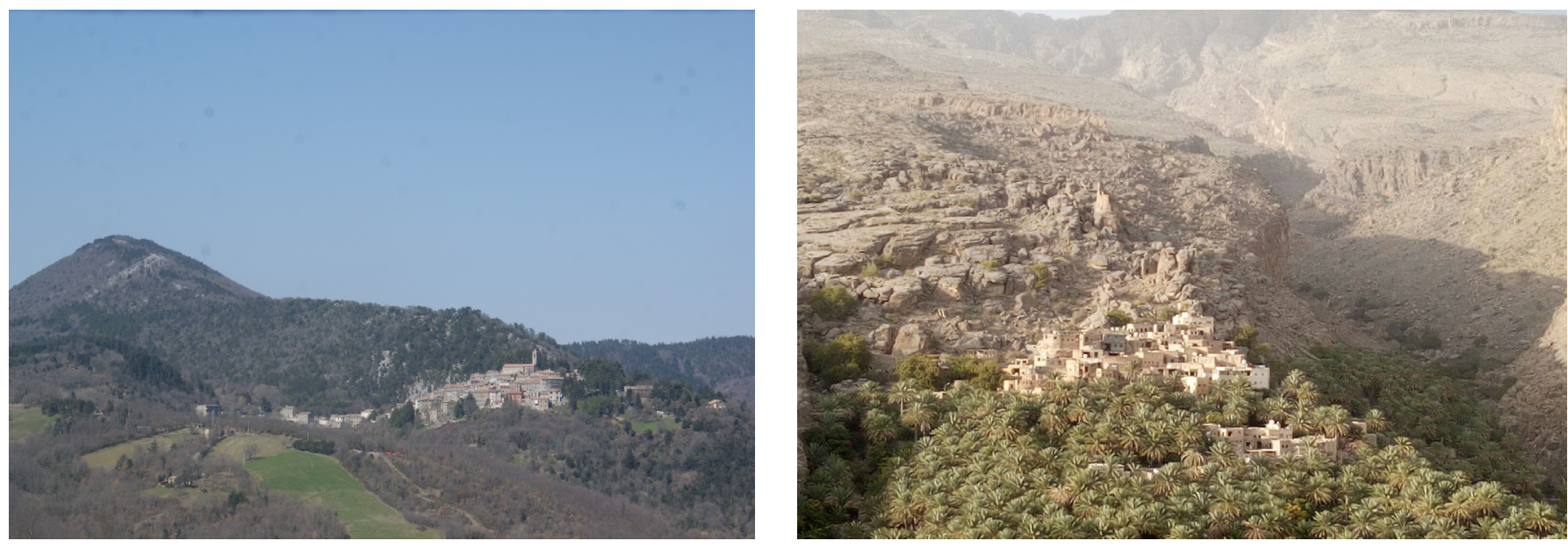

Figure 41, 42. Two examples of good landscape: the design and construction of these structures are perfectly integrated with the terrain (Gerfalco-Italy/ Village in Oman)
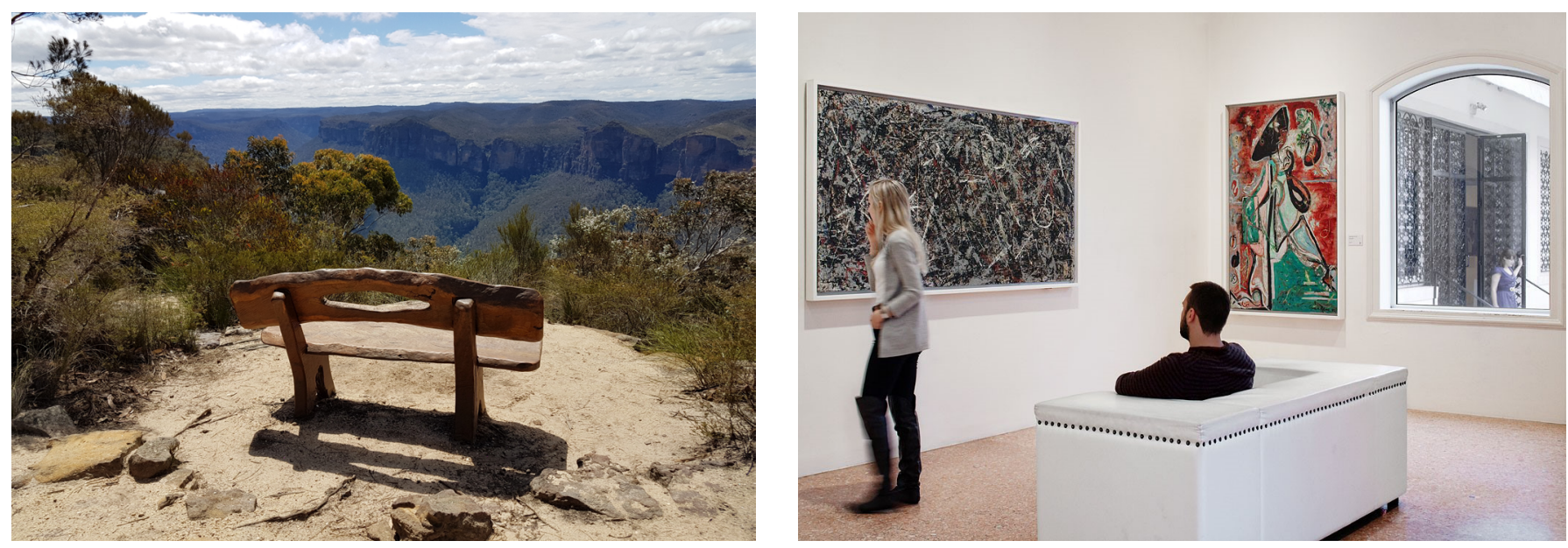

Figure 43,44 . The landscape is art: like in a museum where you sit and enjoy the view 


\section{Architecture and Engineering Volume 2 Issue 1}
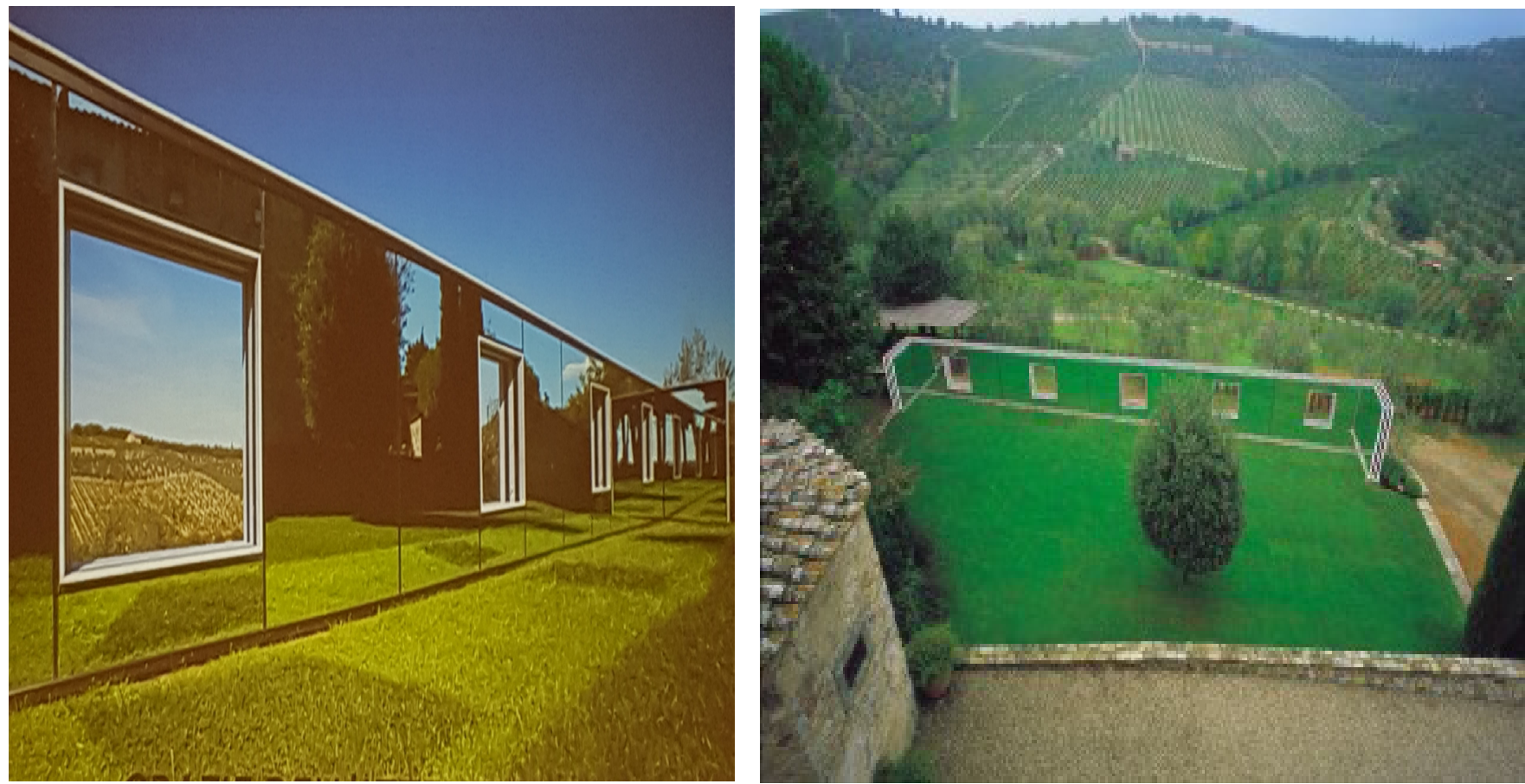

Figure 45, 46. The landscape is art: outdoor eco-museum of the landscape (Chianti)

\section{Landscape and art}

The landscape has a structure of signs and each contains a precise value: the space we see has a precise grammatical reading but always depends on the subject. Science has an objective gaze, while art has a subjective gaze (art shows us the inclinations of our unconscious mind.) The landscape can be interpreted as a product of physical and morphological sedimentation as well as cultural and aesthetic images, making it recognizable and valuable to the perceiver. Some of these striking landscape images, metaphors and figures that have been described through the centuries have come to compose a contemporary aesthetic heritage that are closely linked to the collective recognition and identification of a particular location.

The Tuscan landscape is one of the most famous examples of the process of aestheticism that "invented" a certain image of the terrain. The development of the landscape's importance stems from the stories of writers and the performances of artists in the Anglo-Saxon Grand Tour who describe how they hiked into the Tuscan countryside to find what they felt they had lost in the lives of their neo-industrial cities. That's the vision of the Tuscan countryside and the garden as a work of art.

"People have built the scenery as if they had only its beauty in mind." This is myth: in reality the landscape is beautiful because of a balanced and respectful use of the garden in which modern intensive farming produces a useful livelihood.

The myth of the Florentine painters in the '500s represents medieval-construction. Then the Anglo-Saxon romantic painters emphasized the aesthetic elements of the landscape. The painters of the '900s instead were more realistic by creating a vision of the landscape as seen from the inside (cows, chickens, farm houses.) The Tuscan landscape has always and still evokes agreement that this represents quality of life. And Tuscan wine is the fruit of the beautiful Tuscan landscape.

"Tuscan wine is like a postcard; by drinking the wine and closing our eyes we can see a hill and everything about the countryside come alive. Inside the wine glass is poetry. "And I drink the landscape" said Semboloni Giuseppe, the farmer.

As the great historian Braudel wrote immediately after the Second World War, "The Tuscan landscape is the most touching landscape in the world" and then Desplanques wrote: "The Tuscan countryside was built as a work of art."

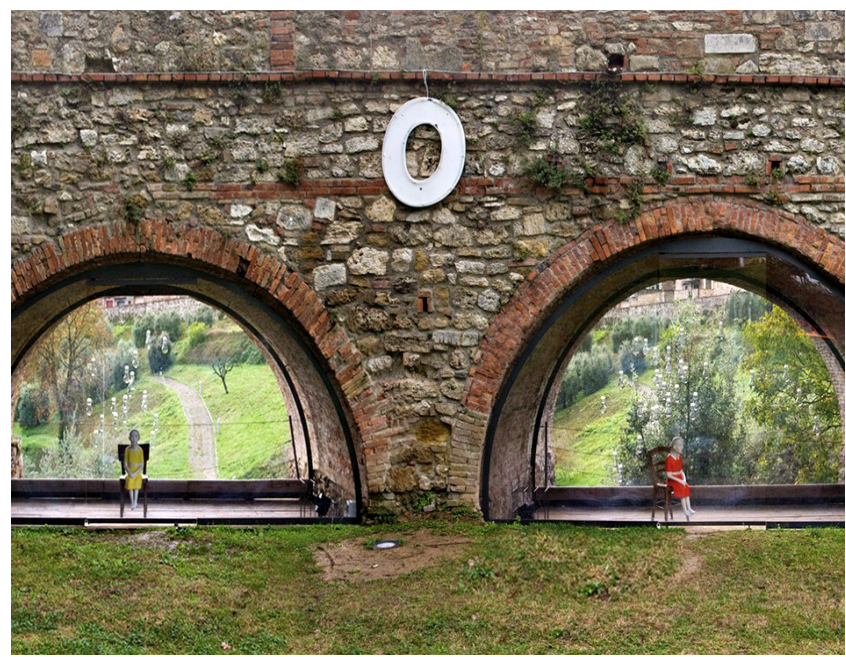

Figure 47. A bridge is used as an art gallery (Colle Val d'Elsa) 


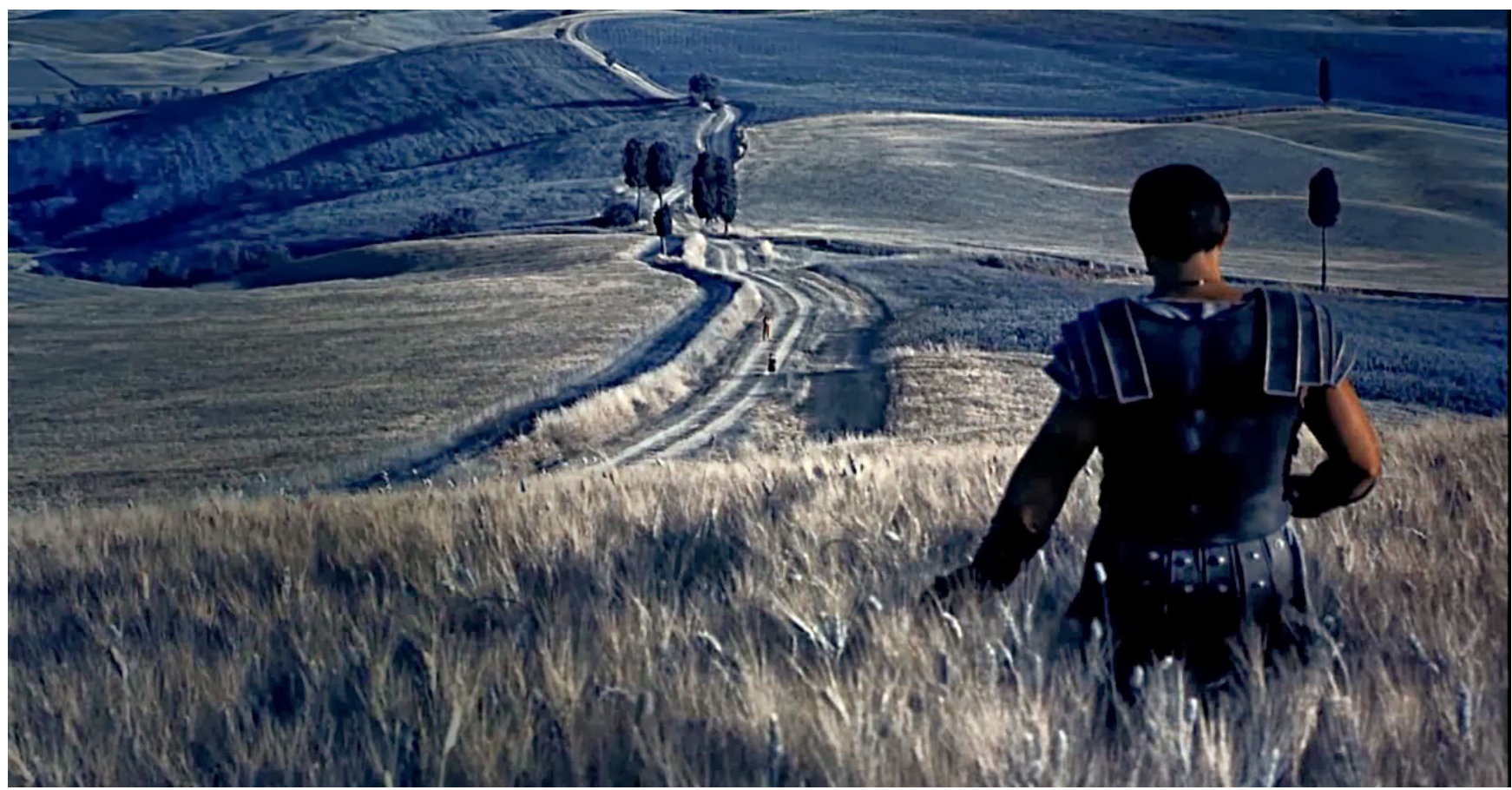

Figure 48. The landscape in cinema: a scene from The Gladiator (2000) (Val d'Orcia-Tuscany-Italy)

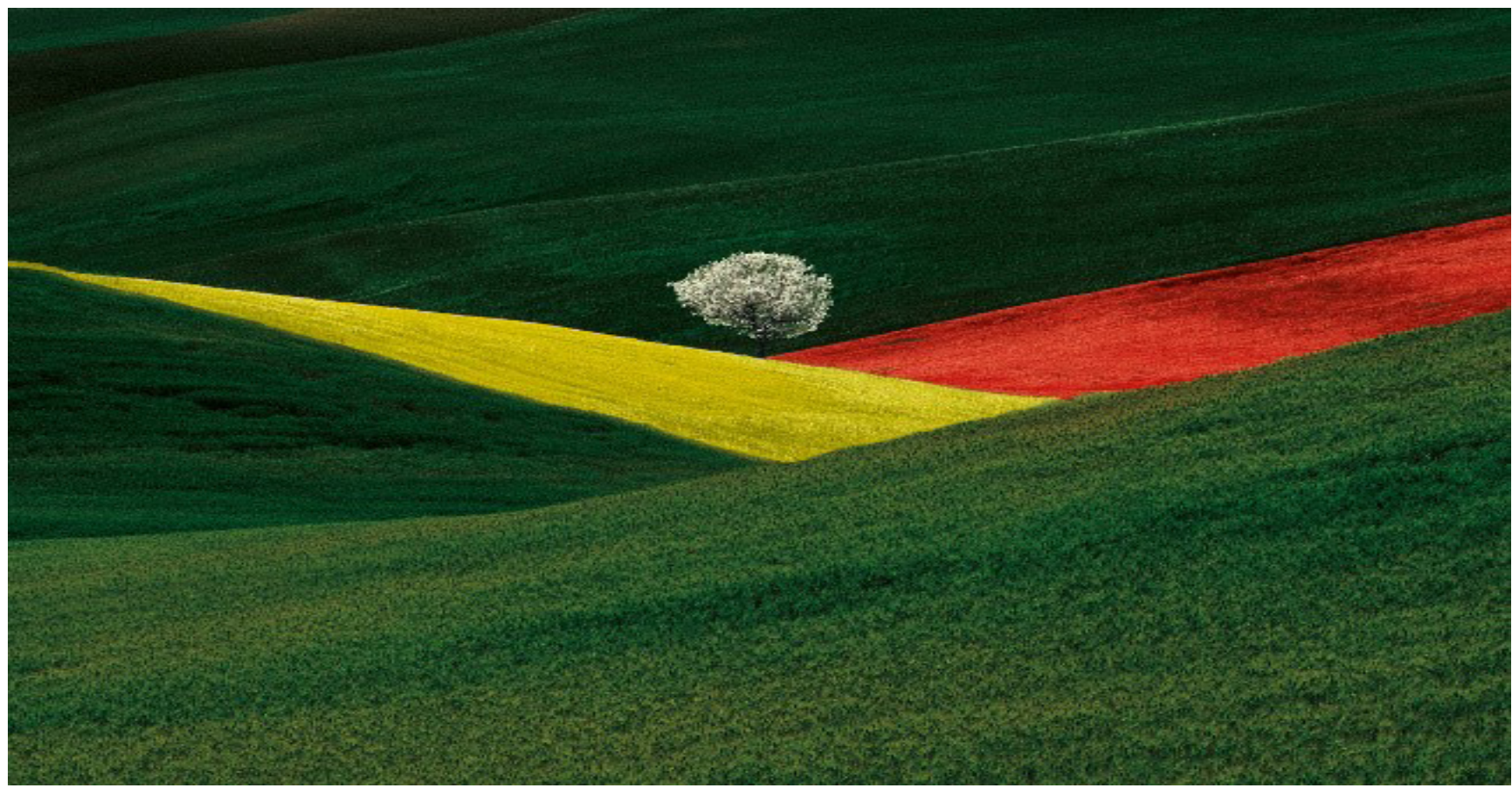

Figure 49. This photo of an landscape can be considered art (Tuscany-Italy) 


\section{The value of the landscape}

So far, we have discussed in this article how the landscape is important for our well-being. We look for places with views that elicit a sense of harmony, vitality or uniqueness: that which is harmonious is not hostile, that which is lively is cheerful, that which is unique introduces novelty and therefore inspires interest. As human beings, we all share the instinct to flee places with views that elicit a sense of disorder, of flatness, or of boredom. A balanced and well cared for landscape produces calmness, psychological safety and aesthetic enjoyment; an imbalanced, mistreated and neglected landscape produces dissonance and discomfort. Dissonance and diversity can produce a beautiful landscape just as in any art form such as poetry, paintings or music, provided they are not frivolous and chaotic. A salient character of the landscape is its identity. A landscape is beautiful even when it is unsettled and transforming; it is unattractive when it contains impurities that are foreign and act like poison that ruin the natural elements or environment of the terrain. For example, imagine a building with a pitched Mediterranean style roof placed on a beautiful, peaceful Tuscan mountain; this should provoke a sense of disharmony since this building would be a discordant element the landscape.

Moreover, it would be simplistic to consider landscapes only as aesthetic sources of enjoyment. If pleasure is an important quality of the landscape, the degree of comfort or discomfort that it produces is linked to more complex and less obvious variables, which are a precondition for a viable countryside. Some ancient ruins can be aesthetically pleasing because they touch a sense of romance that is still present in our culture, however their presence in an open landscape is more functional than it would be in a habitable landscape. A high tech building can be beautiful as a tourist attraction, but can be emotionally draining as a place of work or daily life because it lacks any sense of culture or natural beauty.

The quality of the landscape then comes in varying degrees according to its aesthetic appeal, such as the order, the balance, the diversity the cultural identity the perceiver resonates with as well from as any picturesque disorder.

The Italian landscape is not just a natural phenomena; it has been shaped over the centuries by human activity. This landscape is steeped in history and has been represented by Italian and non-Italian writers and artists in their poetry, paintings and frescoes. In Italy, a different and complementary art form inspired these naturalists to adapt this landscape to their own works of art by applying the concept of a "view," so that a painting of a landscape could evoke positive feelings in almost the same way as those experienced by observing a real landscape from a window or a hill.

Art. Number 9 of the Italian Constitution reads: "the Republic promotes the development of culture and scientific and technical research. Protecting the landscape and the historical and artistic heritage of the Nation." "It's the synthesis of a centuries-old process that has two main features: the public priorities on private property and the close link between protecting cultural heritage and landscape protection," Salvatore Settis wrote.

"In our study of the contexts of landscapes, everything appears solid and stable, the result of the tireless, intricate and endless efforts of human activity. These innumerable, unidentifiable modifications, whose main iconography is preserved, is infinitesimal in the moment and at the time appears relatively unchanged over the course of a human life. It is our landscapes that reveal the quality of our people in a supreme, well organized synthesis of visible memory.. Landscapes are not shapeless masses of the sum of their parts, but complex environmental entities in which millions of involuntary, spontaneous and self-regulated activities have merged into a harmonious whole. This is an anthropological and historical harmony rather than a purely aesthetic or a purely scientific one; we should learn to read, appreciate and care for the landscape, which deserves our education so that we are knowledgeable and understand its proper use," Andrea Caradini (FAl) wrote.

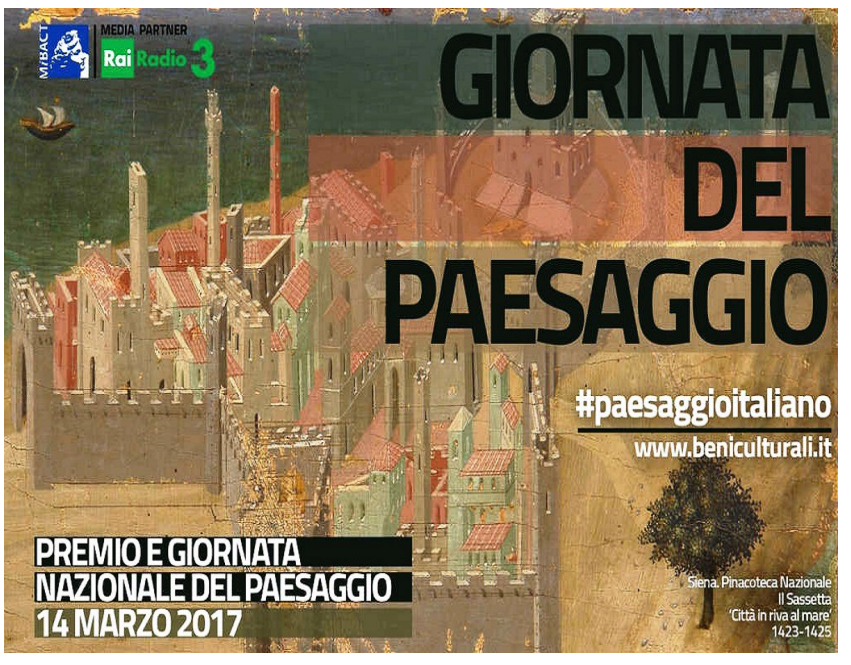

Figure 50. Italian National Day of The Landscape

"The Italian landscape represents all of Italy in its complexity and beauty, and leaves out the interplay between a great nature and a great history, a heritage to defend and even, in large part, to be exploited. The sacredness of the value of the landscape is a regulatory cornerstone; ethical, social and political development is to be defended and protected before and above any development proposal that, if it is detached from these principles, can be invasive, possibly jeopardizing not only to the beauty of the landscape, but also to the present and future functionality of the landscape including tourism," Vittorio Sgarbi wrote.

The protection and enhancement of the landscape safeguards the values that it expresses as a manifestation of cultural identity. In fact, if a landscape is considered to be good and beautiful, in the sense of it being harmonious, orderly or unique, it must also be identified with the place in which it is located. 
Collective identity generates the landscape and the landscape contributes to producing collective identity.

The recognition of the value of a landscape is based on the identification of the following aspects:

-Historical meaning: agrarian spaces represent outstanding examples of a landscape that is associated with a historical period or the most significant periods of our regional history;

-Authenticity and integrity (high, medium, low): landscapes that are present in a given area for a long time, even many centuries;

-Stability or very slow evolution over time: this is evaluated by comparing the maps and aerial photos of the $50 \mathrm{~s}$ with the current ones, with regard to the permanence of key indicators such as the agricultural plot and the network of settlements and local roads;

-Use of practices and techniques related to the tradition: organization characterized by a reduced use of external energy supplies, in terms of automation, irrigation, use of chemical fertilizers and agricultural chemicals;

-Presence of traditional local economic cropping systems;

-Presence of hydraulic-traditional agricultural facilities;

-Presence of a traditional landscape mosaic;

-Significant integrative harmony between productive, environmental and cultural elements.

\section{Landscape as a common good: landscape protection}

The landscape exists as a product of a terrain and as such can't be considered private property; it is common property in the sense that it represents a sense of belonging (identity) in people who see it in person or in art.

Intervention on the landscape should be considered a shared common act: this is why there are rules to preserve the landscape. However, these preservation rules cannot only cover the technical aspects; landscape projects are in fact cultural/humanistic, non-technical initiatives, therefore the correct and appropriate professional for this work is the architect, who has a global vision and understands this to be a great responsibility.

In conclusion, the objectives to be achieved are:

A. MEMORY:

-Keeping alive the memory of our past, recent and distant, the landscape is a clear and tangible sign of how much the history, traditions, local knowledge, social and economic relationships have worked themselves out over the centuries. Identifying and knowing how to read those themes, identifying a syntax, a grammar, a language that binds these elements together would, in our view, act as a contemporary way to understand and share our history and our memories;

- Increasing participation in the theme and study of the landscape;

- To feed our collective, human appetite for a sense of identity and belonging, which we believe to be not only a source of psychological well-being, but also one of "bonding" to the "community."

\section{B. PROTECTION:}

- Protecting means to identify and recognize the landscape as a common good, as a heritage shared by the whole community, to which there are rights but also certain duties;
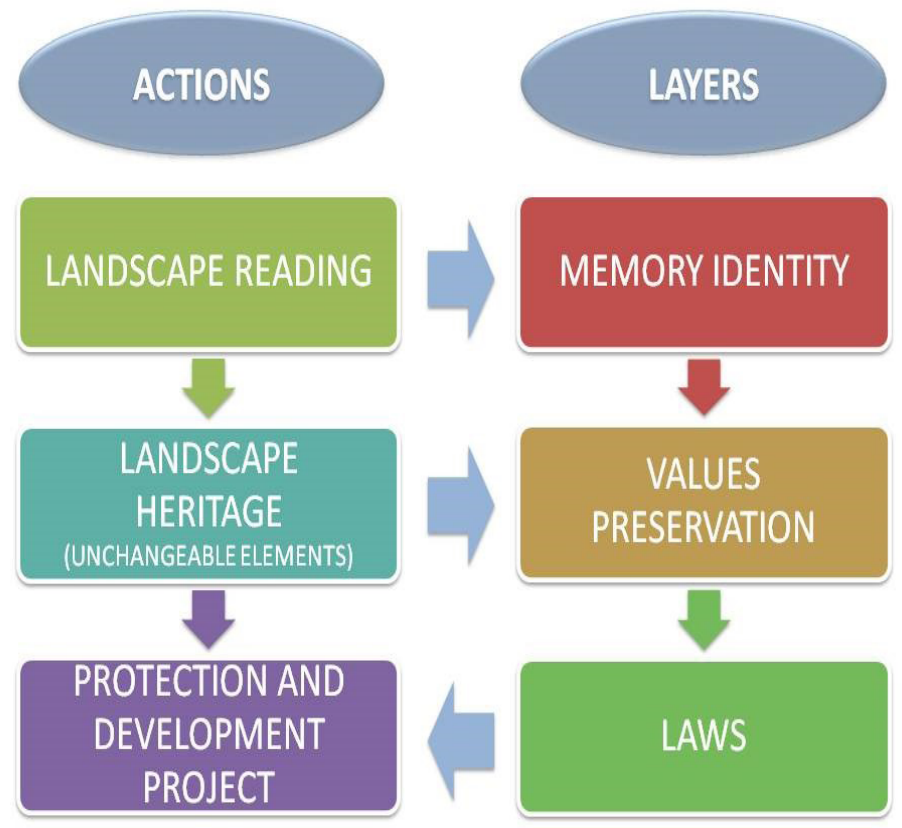

Figure 49. This photo of an landscape can be considered art (Tuscany-Italy) 


\section{Architecture and Engineering Volume 2 Issue 1}

- The biodiversity;

- The ethno-anthropological values.

C. PROJECT:

- Promoting opportunities not only for economic development;
- Supporting visible actions beyond the common focus on excellence and well-known approaches

- Encouraging development according to new growth paradigms;

- Increasing its current resources.
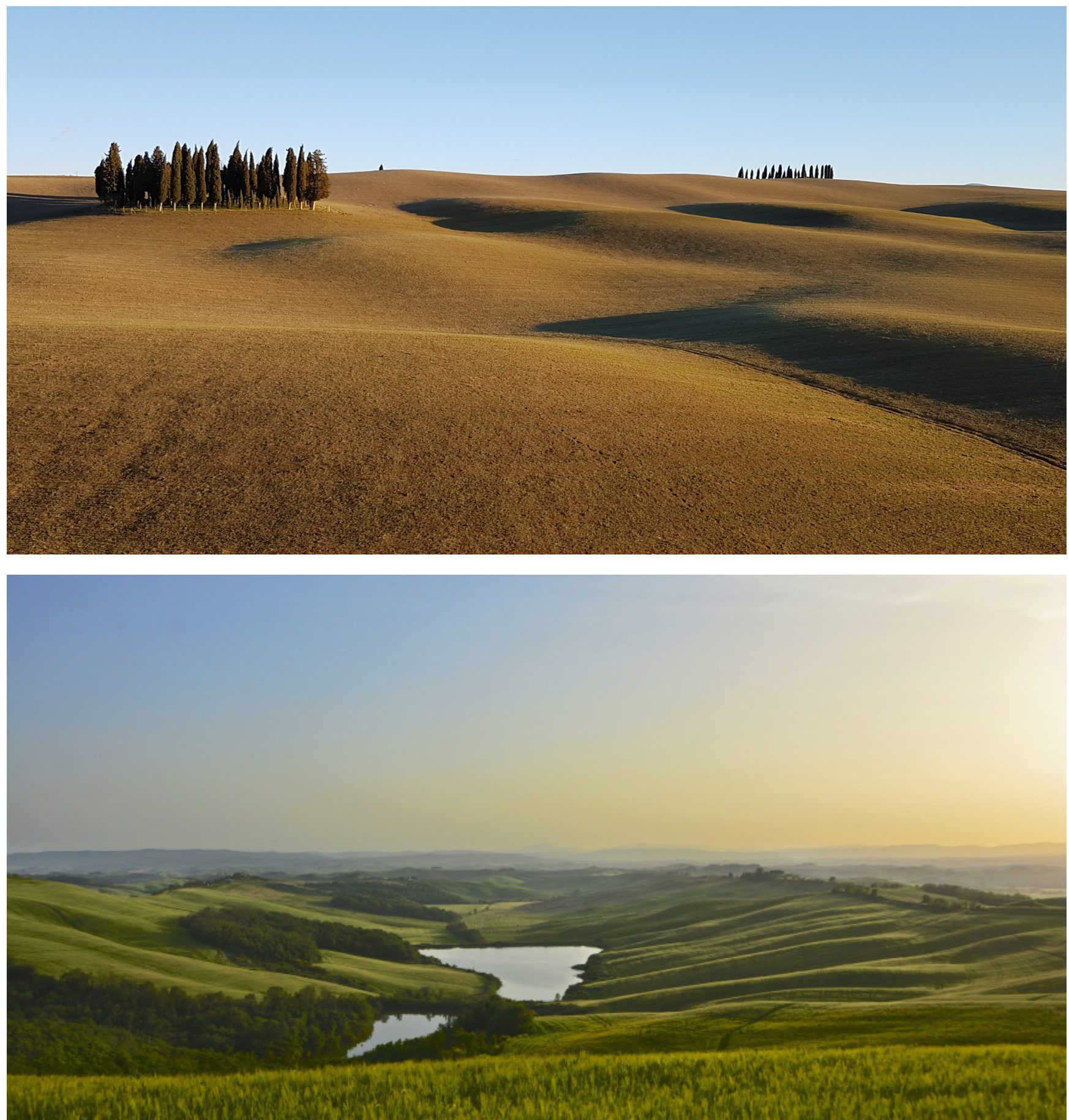

Figure 52, 53. The beauty of the landscape: Val d'Orcia (Siena-Italy). Val d'Orcia is in the UNESCO World Heritage List 


\section{Conclusions}

The landscape is one of the greatest values of our lives: it surrounds us and is always with us; even when we are distracted it is there, waiting for us, waiting for our watchful eyes. We must learn to look at and read the landscape with the "right eye," because when the landscape is read well, we see it in ourselves: in the landscape we find our identity. For this reason it is our duty to safeguard the landscape, not by imposing restrictions on it, but by expanding our knowledge about its physiological changes with wisdom and foresight, because taking action on the landscape is like taking action on a work of art, the fruit of the secular work of humans and nature. The landscape is here for the common good and is an expression of the culture of a place and a society. The landscape is full of history and deserves respect and attention by all those working on one: architects, farmers, farm owners. The scenic beauty is the beauty of our lives: for this reason the landscape deserves that we educate ourselves about its proper use, and become well versed in the wide body of knowledge that has been studied and validated about them.

\section{References}

Agostini, S., Di Battista, V., Fontana, C. (2017). Architettura rurale nel paesaggio [Rural architecture in the landscape]. Santarcangelo: Maggioli Editore, pp. 9-10. (in Italian)

Baldeschi, P. (2011). Paesaggio e territorio [Landscape and spatial]. Florence: Le Lettere pp. 5-25. (in Italian)

Boatti, G. (2014). Un paese ben coltivato [A well cultivated country]. Rome: Laterza, pp. 3-11. (in Italian)

Bonelli Conenna, L., Brilli, A., Cantelli, G. (2004). Il paesaggio toscano: l'opera dell'uomo e la nascita di un mito [The Tuscan landscape: the work of man and the birth of a myth]. Silvana Editoriale pp. 9-12. (in Italian)

Gasperoni, G. (2012). Negli occhi di chi guarda [In the eyes of the beholder]. Rome: Gruppo Editoriale L'Espresso, pp. 11-22. (in Italian)

Jakob, M. (2009). II paesaggio [The landscape]. Bologna: II Mulino, pp. 8-23. (in Italian)

Jakob, M. (2014). Sulla panchina [On the bench]. Torino: Piccola Biblioteca Einaudi, pp. 3-5. (in Italian)

Regione Toscana (2015). Piano Paesaggistico: i paesaggi rurali storici della Toscana [Landscape Plan: historical rural landscapes of Tuscany]. (in Italian)

Resti, G. (2012). Ad occhi aperti: il paesaggio senese tra armonia e cemento [Wide Awake: the Sienese landscape between harmony and cement]. Sienna: Nuova Immagine, pp. 11-18. (in Italian)

Vigueur, J.C.M. (1999). Lettera dal Chianti [Letter from Chianti]. Medioevo magazine, pp. 6-7. (in Italian)

Workshops in Castelnuovo Berardenga (2014). II paesaggio tra passato, presente e futuro [The landscape between past, present and future]. (in Italian)

Workshops in Castelnuovo Berardenga (2015). II paesaggio tra passato, presente e futuro [The landscape between past, present and future]. (in Italian)

Workshops in Castelnuovo Berardenga (2016). II paesaggio tra passato, presente e futuro [The landscape between past, present and future]. (in Italian)

Workshops in Monticiano (Siena) - Pelago (Firenze) - Poggio alla Scaglia (Firenze) - Carmignano (Prato) - Cavriglia (Arezzo) (2016). Guardare al paesaggio: incontri tra visionari [Looking at the landscape: Meetings between visionary]. (in Italian) 